\title{
Space-Time Cluster's Detection and Geographical Weighted Regression Analysis of COVID-19 Mortality Impacts on Texas Counties
}

Jinting Zhang

Wuhan University

Xiu Wu (Dx_w10@txstate.edu )

Texas State University https://orcid.org/0000-0001-8032-3317

T. Edwin Chow

Texas State University San Marcos: Texas State University

\section{Research Article}

Keywords: Geographical Weighted Regression, Space-time cluster's detection, COVID-19, Mortality

Posted Date: May 20th, 2021

DOl: https://doi.org/10.21203/rs.3.rs-525926/v1

License: (1) This work is licensed under a Creative Commons Attribution 4.0 International License.

Read Full License 
Article

\section{Space-time cluster's detection and Geographical Weighted Regression Analysis of COVID-19 Mortality Impacts on Texas Counties}

Jinting Zhang ${ }^{1} \mathrm{Xiu} \mathrm{Wu}^{2 *}$, and T. Edwin Chow

1 School of Resource and Environmental Science, Wuhan University; whuzjt@whu.edu.cn
2* Department of Geography, Texas State University; x_w10@txstate.edu; Tel.: +15127810041
3 Department of Geography, Texas State University; chow@txstate.edu

Abstract: As COVID-19 run rampant in high-density housing sites, it is important to use real-time data tracking the virus mobility. Emerging cluster detection analysis is a precise way of blunting the spread of COVID-19 as quickly as possible and save lives. To track compliable mobility of COVID-19 on a spatial-temporal scale, this research is appropriately analyzed the disparities between spatial-temporal clusters, expectation Maximization clustering (EM) and hierarchical clustering (HC) analysis on Texas county-level. Then, based on the outcome of clustering analysis, the sensitive counties are Cottle, Stonewall, Bexar, Tarrant, Dallas, Harris, Jim hogg, and Real, corresponding to Southeast Texas analysis in GWR modeling. The sensitive period took place in the last two quarters in 2020. We explored Postgre application to portray tracking Covid-19 trajectory. We captured 14 social, economic, and environmental 14 impact's indices to perform Principal Component Analysis (PCA) to reduce dimensionality and minimize multicollinearity. By using the PCA, we extracted five factors related to mortality of COVID-19, involved population and hospitalization, age structure, natural supply, economic condition, air quality and medical care. We established the GWR model to seek the sensitive factors. The result shows that population, hospitalization, and economic condition are the sensitive factors. Those factors also triggered high increase of COVID-19 mortality. This research provides geographical understanding and solution of controlling COVID-19, reference of implementing geographically targeted ways to track virus mobility and satisfy for the need of Emergency Operations Plan (EOP).

\section{Introduction}

The coronavirus disease 2019 (COVID-19), as a global disaster, stopped at social-economic development worldwide in 2020. It has threatened the loss of human life, public health, safety, and disruption of face-to-face communication due to intangible, clinical severity of the infection and fatal symptoms [1]. By March $11^{\text {th }}$ of 2021, there are 2.62 million lost their lives around the world, accounting for $15 \%$ of World War One fatality. A pervasive sense of quarantine fatigue and panic attacks of getting infected are challenging human resilience [2-3]. COVID-19 is one of the extreme diseases as incurable and universally fatal, killing $25 \%-50 \%$ of patients [4]. In particular, the COVID-19 pandemic in the U. S. was exposed to mass dislocation, directly accelerating the decline and failure of public health. With around 30 million diagnosed cases and over 540,000 deaths as of mid-January 2020, a disproportionate impact on COVID-19 was produced. There are $40 \%$ of cases should have been averted with international cooperation of medical care [4]. In addition, agespecific mortality rates in the US had remained corresponding to the weighted average of G7 nations [4].

Texas is the second-largest state in the U.S. and has one-tenth of the aging people. Despite unremitting Texas Executive Orders (TEO) and Public Health Disaster Declarations (PHDD) were made, the Texas government maintained economic openness. The first COVID-19 case in the United States was confirmed on January 19th 2020, in Washington State [5], whereas the first case was announced by The Texas Department of State Health Services on March $4^{\text {th }}$ in Fort Bend County. As of 02/28/2021, Texas surpasses 2,300,000 total COVID-19 cases and 372,086 deaths cases. As US has gone through several waves of epidemic cycles, Texas has undergone all 5 stages of COVID-19 risk-based guidelines. 
Texas disease surveillance and response systems have disclosed the vulnerability to deal with the global pandemic, which underlines the requirement to establish global scheme, regulation and collaboration [6]. A silver lining is that the pandemic provides a unique and empirical opportunity to observe a large-scale and prolonged episode of public health emergency. Accordingly, it is imperative to understand the spatial-temporal clusters of COVID-19 mortality and explored its relationships with environmental and social-economic factors.

A popular statistical tool to look into that relationship is space-time scan statistic, which is widely used to quantify cluster strength and statistical significance [7]. Epidemic surveillance and spatiotemporal trending analysis can provide unique insights for decision makers to be aware of potential uptakes and adopt proactive public health measures to mitigate the risk and minimize COVID-19 infection. Detecting patterns of COVID-19 confirmed cases and mortality in the United States are well documented to formulate interventions, targeted rapid testing, and resource allocation [8-10]. However, the usefulness of space-time analysis depends on the data quality (e.g., accuracy, spatial resolution, temporal currency, completeness, etc.), which are somewhat limited at the early stages of pandemic. Besides, Desjardins mentioned deaths could be conducted, but not incorporated in the research scope. Those spaces are filled in our study. The distribution of the COVID-19 pandemic is well represented by GIS spatial analysis with the multidimensional social, economic, and health consequences, exposing to geographical inequity and a long-term impact on global health accurately [11-13]. GIS-driven spatial analysis can facilitate the combination between health data and characteristic of spatial attributes. Descriptive modeling research that took advantage of those strength has deeply exposed the spatial-temporal associations of COVID-19 with socioeconomic and environmental characteristics [14-15]. However, as far as an engaging empirical study, it is important to select variables that reveal the degree of social vulnerability [16-18].

Spatial-temporal analysis of COVID-19 is crucial to understand the spread of COVID-19 and explore appropriate community containment strategies, which are fundamental public health measures used to control the spread of communicable diseases, including isolation and quarantine. This paper focuses on the county level within a state to eliminate the possibility of policy divergences between states, since existing research spatial-statistically calculated countylevel data, but not temporal lag disparity of county-level [19-23]. Due to varying social vulnerability associated with different population demographics, such as age, gender, and race/ethnicity, some population groups are more vulnerable in the threat of COVID-19. A few variables are presented in the previous modeling [24-29], albeit population mobility, age, race were significant factors [30-36]. As a respiratory disease, air pollution indices like PM2.5 and Air Quality Index (AQI) are highly related to COVID-19. Despite air quality, Qian contends, is viewed as a robust interaction with COVID-19 [37], AQI and PM2.5 have not been explored in previous spatial-temporal models, only added as impacts factors on the environmental list [38-42].

The research purposes are of two folds - first, to identify any emerging space-time clusters of COVID-19, and second, to examine any significant factors related to mortality. By exploring the spatiotemporal clusters based on a more comprehensive set of data over a year-long period, this research examines the correlation between COVID-19 mortality rate and social-economic, environmental factors with GWR analysis. It aims to identify sensitive indicators to assist the formulation of targeted intervention suitable for vulnerable populations and break the chains of transmission. Hence, this research is expected to provide references for preventing and controlling COVID-19 and related infectious diseases, evidence for disease surveillance, and response systems to facilitate the appropriate uptake and reuse of geographical data, to contribute to safeguarding Texas public health. Our long-term goal is to improve and strengthen health seamless connection and surveillance system by timely dynamic monitor mechanism.

\section{Materials and Methods}

\subsection{Data}

COVID-19 mortality is the subject of observation in the space-time scan statistic. The COVID-19 mortality rate as the dependent variable is acquired from the Centers for Disease Control and Prevention (CDC), COVID-19 fatality data based on death certificates. A fatality is counted as a COVID-19 fatality when the medical certifier attests to the death certificate that COVID-19 is a cause of death. Mortality rate is equal to fatalities divide by cumulative cases. Hospitalization (i.e., total hospital bed, bed per capital) from The Texas Department of State Health Services (DSHS) is reported daily by hospitals through eight Hospital Preparedness Program providers that coordinate health care system preparedness and response activities in Texas. The data were collected from March $4^{\text {th }}, 2020$ to March $1^{\text {st }}$ in 2021 as explanatory variables. Demographic data, such as race, age group, gender, population density, are acquired from the 2020 U.S Census Bureau. Economic data (e.g., annual income) during 2020 are obtained from the Texas Association of Counties, the 
statistical period is 2020. Environmental data are interpolated from limited samples collected by the United States Environmental Protection Agency (i.e., AQI, PM2.5) and National Weather Service (i.e., temperature, precipitation) during $3 / 1 / 2020-2 / 28 / 2021$. All variables are in Table 1.

Table 1. A-List of Variables Used for Geostatistical Analysis

\begin{tabular}{|c|c|c|c|}
\hline $\begin{array}{l}\text { Variable } \\
\text { category }\end{array}$ & Variable name & Acronym & Variable description \\
\hline \multirow[t]{2}{*}{ Economic } & Annual income & PCI & Median Household Income \\
\hline & Unemployment & UEM & Percent of residents who don't have job \\
\hline \multirow[t]{5}{*}{ Environmental } & Precipitation & $\mathrm{PCN}$ & Mean precipitation per month \\
\hline & Temperature & TPE & Mean temperature per month \\
\hline & PM2.5 & PM2.5 & Mean PM2.5 per day \\
\hline & Air quality & AQI & Mean air quality per day \\
\hline & Land Area & LA & Total land area per county \\
\hline \multirow[t]{6}{*}{ Demographic } & Population density & POD & Population density \\
\hline & Total population & $\mathrm{TP}$ & Total population \\
\hline & Male population & PMP & Percent of residents who are male \\
\hline & Black population & PBP & Percent of residents who are black \\
\hline & Populationbetween20-59 & P59 & Percent of residents who are between 20-59 \\
\hline & Population beyond 80 & P80 & Percent of residents who are beyond 80 \\
\hline \multirow[t]{2}{*}{ Health } & Total hospital beds & THB & Total hospital beds \\
\hline & Beds per capital & $\mathrm{BPC}$ & Incidents per 1,000 residents \\
\hline \multirow[t]{2}{*}{ Covid-19 } & Fatalities & $\mathrm{TF}$ & Total death number \\
\hline & Mortality Rate & MR & Percent of fatalities case on total case \\
\hline
\end{tabular}

2.2 Study Framework

From a temporal study framework perspective, the study period was classified into four boxes based on the number of fatalities (TF) per quarter. Quarterly statistical data are based on environmental and socio-economic indices at the end of each quarter in response to COVID-19 fatalities at that time. The temporal-study framework in Fig 1.

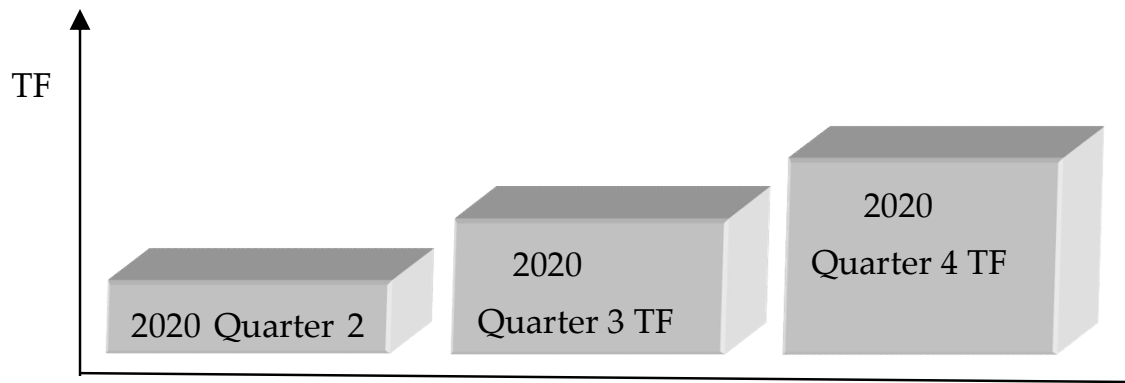

Fig. 1 Temporal-Study Framework

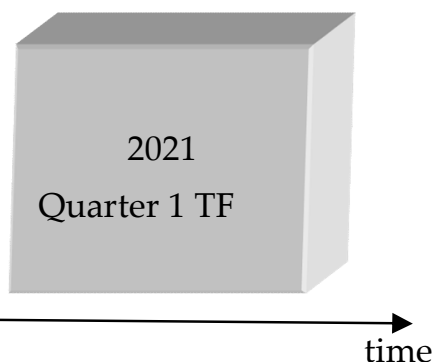

For the spatial study, we explore the inter-correlations among independent variables before building the GWR models. Since dependent variables must meet the assumption of a normal distribution, we have to describe their statistical characteristics and spatial autocorrelation analysis. To minimize any multicollinearity, all explanatory variables are standardized and examined by Principal Component Analysis into composite factors. After that, we try to model simple Ordinary Lease Square (OLS) and geographically weighted regression between variables. Finally, via model comparisons, we pay more attention to their differences in spatial heterogeneity and analyze how did it happen, as shown in Fig.2. 


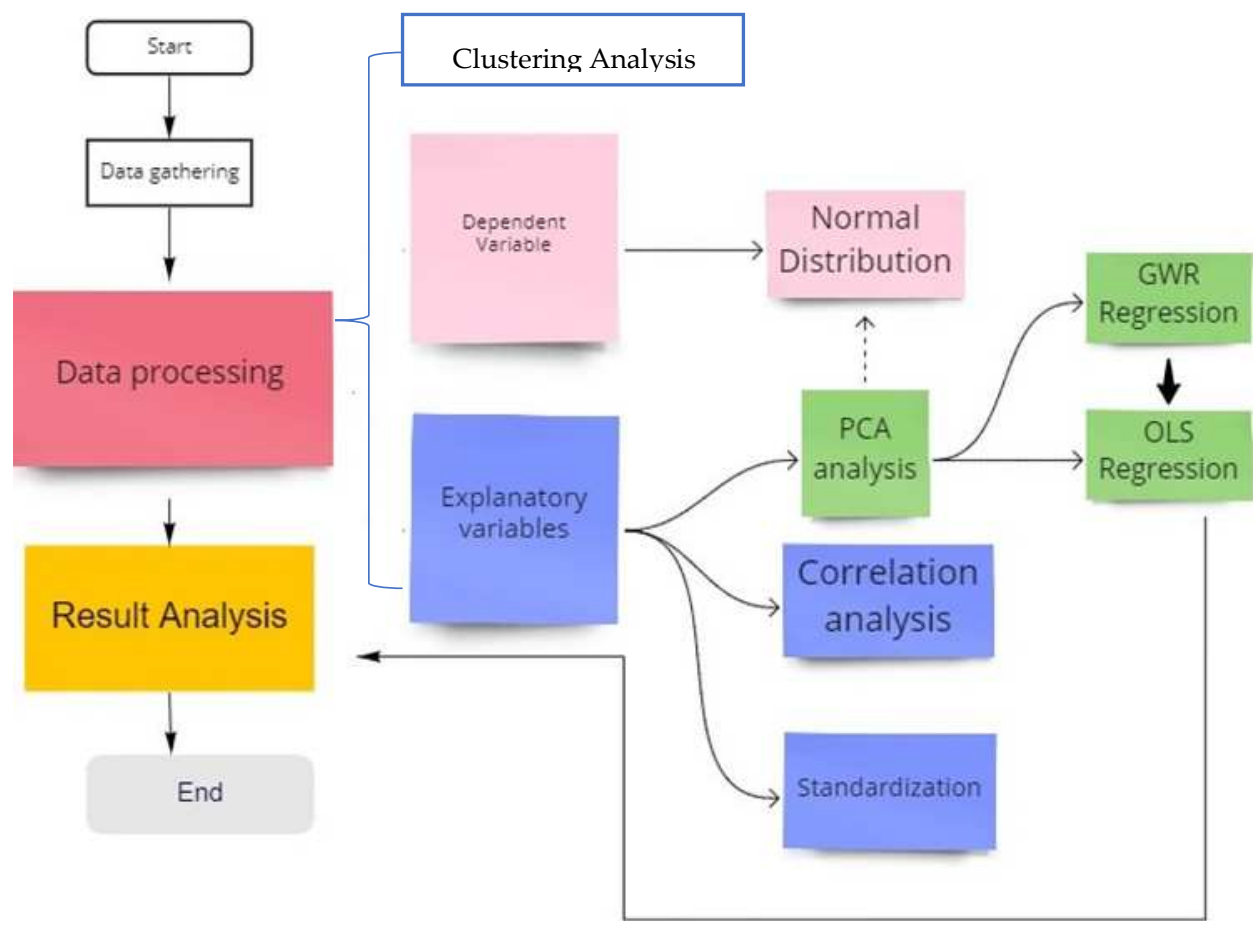

Fig 2 Spatial study framework

\subsection{Space-time Scan Statistics}

In Kulldorff's scan statistic method, the first step is to determine a congruous probability model of data, then compute the likelihood ratio test statistic $\lambda(\mathrm{z})$ for each scan window z. After that, we identify primary cluster candidates with the maximum $\lambda(\mathrm{z})$, a Monte Carlo hypothesis procedure tests the statistical significance and obtains a p-value [43]. On one hand, Kulldorff's method tests the null hypothesis $\mathrm{H}_{0}$ (constant probability for all areas) and the alternative hypotheses $\mathrm{H}_{1}$ (the specific area $\mathrm{z}$ has a larger probability than outside areas) using a Poisson model[7]. For a given region $z$, the likelihood function based on the Bernoulli model can be expressed using expression (1):

$$
L(z)=\sup _{p>q} L(z, p, q)=(p)^{n z} \times(1-p)^{\mu(z)-n z} \times q^{n G-n Z} \times(1-q)^{(\mu(G)-\mu(z))-(n G-n Z)}
$$

where, $\mu(G)$ and $\mu(Z)$ are the total population of the study area and population in region $Z$; nG and nZ are the total numbers of observed cases in the study area and in region $Z ; p$ is the probability that an incident falls in region $Z$, and

$$
L(z)=\left\{\begin{array}{c}
\text { sup } L(z, p, q)=\hat{p}^{n Z} \times(1-\hat{p})^{\mu(Z)-n Z} \times \hat{q}^{n G-n Z} \times(1-\hat{q})^{(\mu(G)-\mu(z))-(n G-n Z)} \text { if } \hat{p}>\hat{q} \\
\hat{p}_{0}^{n G} \times\left(1-\hat{p}_{0}\right)^{\mu(G)-n G}
\end{array}\right.
$$

Where, ${ }_{0}^{\hat{p}}=\frac{n G}{\mu(G)^{\prime}}, \hat{p}=\frac{n Z}{\mu(z)}$, and $\hat{q}=\frac{n G-n Z}{\mu(G)-\mu(z)}$. The expected likelihood function has the form as given in expression (3):

$$
\mathrm{L}_{0}=\sup _{\mathrm{p}=\mathrm{q}}^{\mathrm{su}} \mathrm{L}(\mathrm{Z}, \mathrm{p}, \mathrm{q})=\left(\frac{\mathrm{nG}}{\mu(\mathrm{G})}\right)^{\mathrm{nG}} \times\left(\frac{\mu(\mathrm{G})-\mathrm{nG}}{\mu(\mathrm{G})}\right)^{\mu(\mathrm{G})-\mathrm{nG}}
$$

Therefore the likelihood ratio $\lambda(\mathrm{z})$ can be obtained as the quotient by dividing the observed likelihood by expected likelihood:

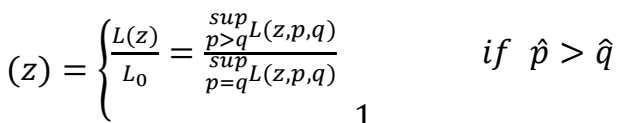

Kulldorff (1997) also gave the formula to calculate the likelihood ratio based on the Poisson model as shown below [7]: 


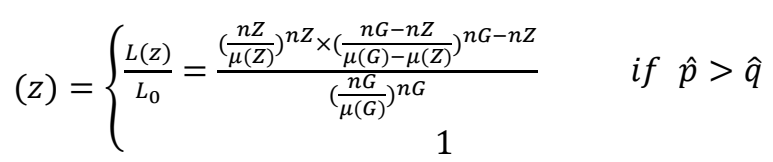
on Foster's spatial varying parameter regression, a Geographically Weighted Regression model (GWR) is localized 
through weighting each observation in the dataset [54]. It, pointed out by Fotheringham, was used local smooth processing to address the spatial heterogeneity. Under the consideration of spatial disparity, geographic coordinates and core functions are utilized to carry out local regression estimation on adjacent individuals of each group. The equation of the GWR fitted model is as follows [55].

$$
\mathrm{y}_{\mathrm{i}}=\beta_{0}\left(\mathrm{u}_{\mathrm{i}}, \mathrm{v}_{\mathrm{i}}\right)+\sum_{\mathrm{k}} \beta_{\mathrm{k}}\left(\mathrm{u}_{\mathrm{i}}, \mathrm{v}_{\mathrm{i}}\right) \mathrm{x}_{\mathrm{k}, \mathrm{i}}+\varepsilon_{\mathrm{i}}(7)
$$

Where i denotes the individual sample; $\left(\mathrm{u}_{i}, \mathrm{v}_{\mathrm{i}}\right)$ is the coordinates of sample $\mathrm{i} ; \beta_{\mathrm{k}}\left(\mathrm{u}_{i}, \mathrm{v}_{\mathrm{i}}\right)$ is the kth regression parameter of sample $i$; $y_{i}$ is the dependent variable of sample $i, x_{k}, i$ is the $k_{\text {th }}$ independent variable for the sample $i, \varepsilon_{i}$ is random error term which obeys normal distribution when the variance is a constant, thus the parameter estimation value of sample $i$ is given by:

$$
\hat{\beta}\left(u_{i}, v_{i}\right)=\left(X^{T} W\left(u_{i}, v_{i}\right) X\right)^{-1} X^{T} W\left(u_{i}, v_{i}\right) y
$$

where $\mathrm{W}$ is the spatial weight matrix, whose selection and setting are the core issues of GWR regression. The calculation of GWR coefficients consists of two major steps - first by selecting a proper kernel function to express the spatial relationship between the observed units. Specifically, four major kernel functions are being used in existing research, namely fixed Gaussian, fixed Bi-square, adaptive Bi-square, and adaptive Gaussian. Since the merits of a kernel function play a direct and decisive role in obtaining the most accurate possible regression parameter estimation of spatial heterogeneity, after careful analysis and comparison, fixed Gaussian was chosen as the kernel function in the paper, which is expressed as,

$$
\mathrm{w}_{\mathrm{ij}}=\exp \left(-\mathrm{d}_{\mathrm{ij}}^{2} / \theta^{2}\right)
$$

where $\mathrm{w}_{\mathrm{ij}}$ represents the distance weight from sample $\mathrm{i}$ to sample $\mathrm{j}$; $\mathrm{d}_{\mathrm{ij}}$ is the Euclidean distance between sample I and sample $j ; \theta$ is the bandwidth, which determines the speed at which the spatial weight attenuates with distance. The second step of spatial weight matrix calculation is the selection of optimal bandwidth which could contribute to a higher fitting degree. According to the GWR4.09 User Manual [56], bandwidth selection criteria include AIC (Akaike Information Criterion), AICc (small sample bias-corrected AIC), BIC, and CV (Cross Validation).

3.1. Space-time Scan Statistics

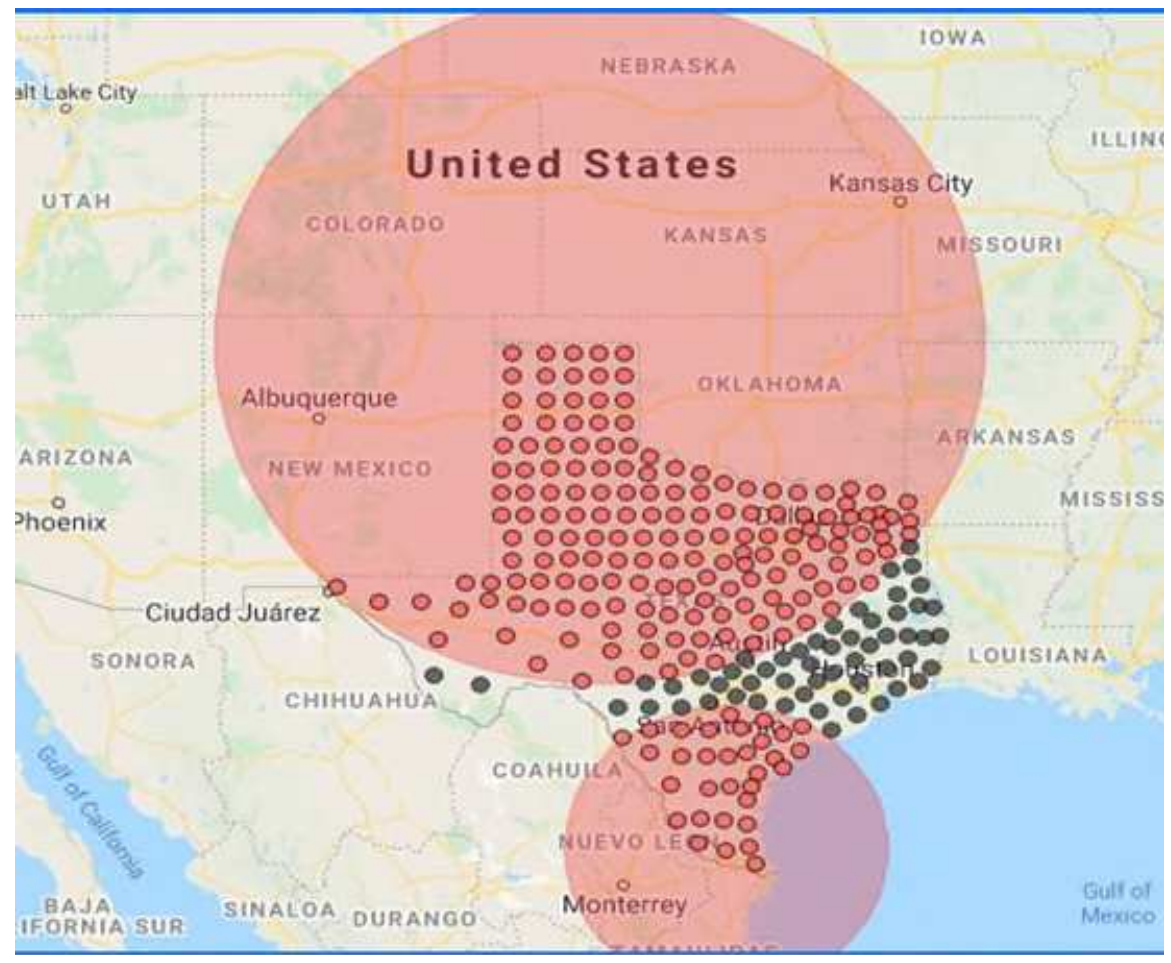


Fig 3. Space-time clusters distribution Map

By using SaTCan software, two significant space-time clusters of COVID-19 were detected at 0.05 level (Fig 3; Table 2). The bigger cluster incorporates 172 counties of 13,085,347 population and 12,761 new cases, covering the northern and western Texas. During the period of 2020/11/6-2021/2/5, this cluster observed COVID-19 cases that were 2.48 times more than expected cases. The second cluster centers around East Texas and involves 27 counties with $26,217,888$ population and 3,635 new cases during 2020/7/6-2020/9/5. This eastern cluster has an observed/expected ratio of 5.23 times. It is noted, however, that this eastern cluster took place during the earlier stage of the pandemic when the COVID-19 cases had just started spreading in Texas and hence the expected cases were lower than the northern cluster. Among the 254 counties in Texas, these two clusters occupied 199 counties. The spatial extent of these clusters is too large to guide precise tracking of COVID-19 mortality.

Table 2 Cluster comparison Table

\begin{tabular}{ccc}
\hline Items & Cluster 1 & Cluster 2 \\
\hline Time frame & $2020 / 11 / 6$ to $2021 / 2 / 5$ & $2020 / 7 / 6$ to $2020 / 9 / 5$ \\
\hline Population & $13,085,347$ & $26,217,888$ \\
\hline Neighborhood & 172 counties & 27 counties \\
\hline Log-likelihood Ratios & $4,084.27$ & $3,072.54$ \\
\hline Number of cases & 12,761 & 3,635 \\
\hline Expected cases & $5,147.24$ & 695.01 \\
\hline Observed/ expected & 2.48 & 5.23 \\
\hline Relative risk & 3.08 & 5.61 \\
\hline P-value & $<0.0001$ & $<0.0001$ \\
\hline
\end{tabular}

\section{Cluster \#1}

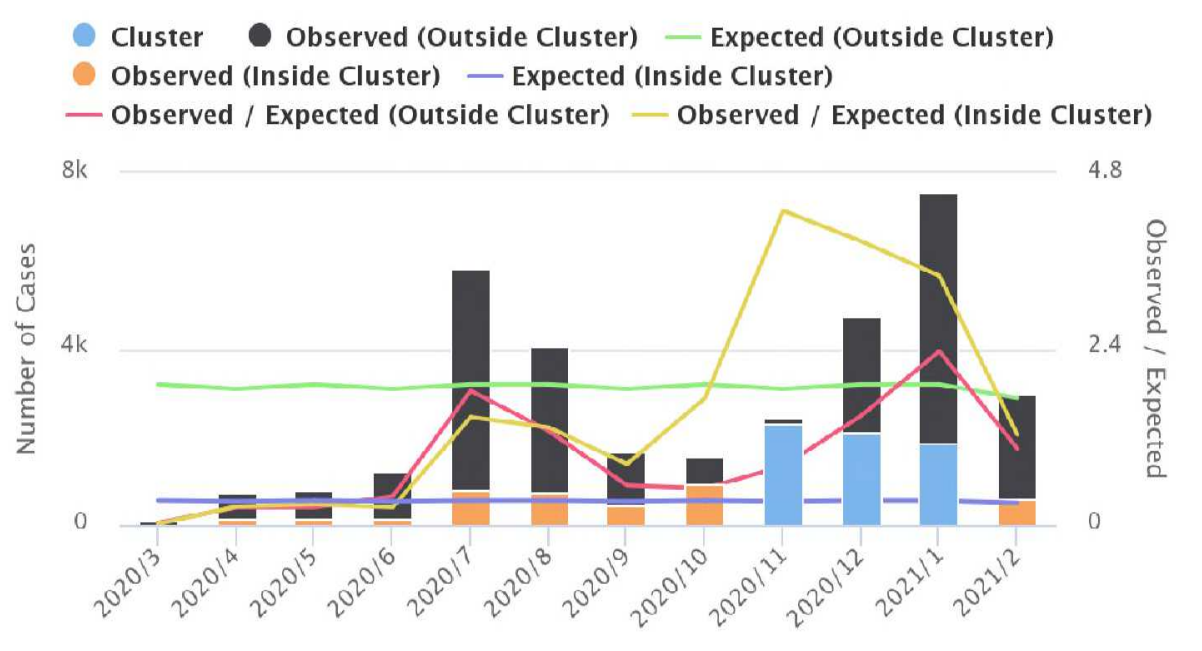

Fig 4 Temporal trend

Focusing on the temporal trend, November 2020 is the most serious month during the 3 months space-time cluster in the northern and western Texas (Fig 4). According to the above Fig.4, the highest month of the proportion of observed/ expected cases is shown in November 2020. Hence, the cluster period is confirmed in the last two quarters of 2020 and the first quarter of 2021, and the cluster's locations were covered 199 counties, which is the key of the following GWR analysis. 


\subsection{EM clustering and HC clustering}

Based on mortality rate alone, the EM algorithm identified seven clusters in the third quarter that are not significant (Table 3). In the last quarter, eleven clusters are produced, including seven significant clusters and four insignificant clusters. The maximum log likelihood is -86.34. In HC clustering, the cases are classified as cluster 0 and cluster 1.

Cluster 0 means 4 counties as a group in the third quarter and 8 counties as a group in the last quarter, including Cottle, Stonewall, Bexar, Tarrant, Dallas, Harris, Jim hogg, and Real. Incorrectly Clustered instance are 251 counties in the third quarter and 247 counties in the last quarter. Two clustering methods selected classes to cluster evaluation parameters. They are prior to the previous space-time cluster detection due to narrow county scales.

Table 3 The EM clustering and HC clustering analysis Table

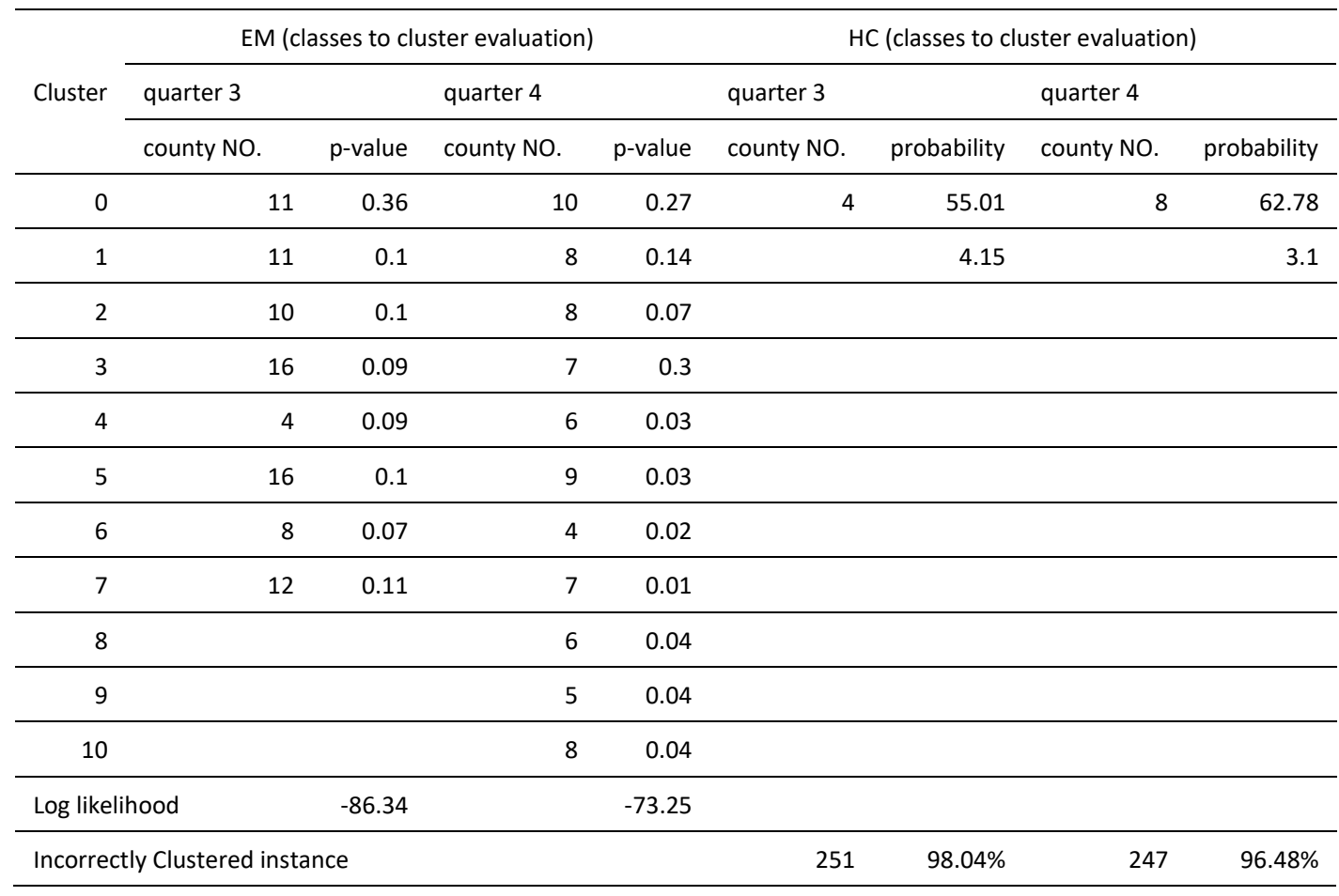

Table 4. Correlation List

\begin{tabular}{ccc}
\hline $\begin{array}{c}\text { Explanatory } \\
\text { Variables }\end{array}$ & Quarter 3 & Quarter 4 \\
Coe./Sig. & Coe./Sig. \\
\hline TPE & $-0.265 / 0.000^{* *}$ & $-2.11 / 0.001^{* *}$ \\
\hline PCN & $-0.251 / 0.000^{* *}$ & $-0.166 / 0.008^{* *}$ \\
\hline
\end{tabular}




\begin{tabular}{ccc}
\hline AQI & $-0.121 / 0.054$ & $-0.062 / 0.325$ \\
\hline THB & $-0.145 / 0.020^{*}$ & $-0.176 / 0.005^{* *}$ \\
\hline BPC & $-0.007 / 0.908$ & $-0.018 / 0.781$ \\
\hline POD & $-0.203 / 0.001 * *$ & $-0.247 / 0.000^{* *}$ \\
\hline LA & $-0.074 / 0.241$ & $-0.092 / 0.146$ \\
\hline PCI & $0.147 / 0.019^{*}$ & $-0.111 / 0.078^{* *}$ \\
\hline TP & $-0.176 / 0.005^{* *}$ & $-0.215 / 0.001 * *$ \\
\hline PBP & $-0.191 / 0.002^{* *}$ & $-0.082 / 0.194$ \\
\hline UEM & $-0.106 / 0.093$ & $-0.046 / 0.471$ \\
\hline PMP & $0.011 / 0.857$ & $0.020 / 0.746$ \\
\hline P59 & $-0.300 / 0.000 * *$ & $-0.250 / 0.000 * *$ \\
\hline P80 & $0.243 / 0.000^{* *}$ & $0.183 / 0.003 * *$ \\
\hline$* *$. Correlation is significant at the 0.01 level (2-tailed). \\
**. Correlation is significant at the 0.05 level (2-tailed). \\
\hline
\end{tabular}

3.5 Factor analysis

Through PCA, the dataset was examined using Kaiser-Meyer-Olkin (KMO) and Bartlett's Test of Sphericity. The $\mathrm{KMO}$ test compares the correlation statistics to identify if the variables include sufficient differences to extract unique factors. A KMO value of 0.616 for 14 explanatory variables is more than the threshold value of 0.5 , The Bartlett's Test of Sphericity (BTS) value of 0.0 was significant $(\mathrm{p}<0.001)$, validating that correlation between variables does exist in the population. Communality is a common variance between 0 and 1 , using the remaining variables as factors, was used to determine if any variables should be excluded from the factor analysis (Table 5). A 0.7 threshold is used to determine the significance of explanatory variables.

PCA was conducted as the factor analysis method in this paper. Using an eigenvalue threshold greater than 1.0, 5 factors are identified that could explain a cumulative $70.18 \%$ of the variance within the data model (table 6). A varimax rotation was used to assist in the interpretation of the PCA analysis. The rotated component matrix was examined for variables with a cutoff threshold of 0.7 . Table 6 gave us the direct relationship between factors and explanatory variables. The first factor, in three quarters, represents high loading on variables related to Care Beds, Total Population, Population Density, indicating the COVID-19 mortality rate is positively related to hospitalization and total population. That means the metric of population and the index of medical care are two main indicators of COVID-19. Factor 2 in the third quarter of 2020, factor 4 in the first quarter of 2021andfactor 4 in the fourth quarter of 2020 were a composite adult population index related to the population between 20-59 and beyond 80Factor 3 in two quarters of 2020 and factor 2 in the first quarter represent natural supply index, which related to land area and precipitation, indicating keeping social distancing was helpful to mitigate MR. The economic condition indexes include Factor 4 in the third quarter, factor 2 in the fourth quarter, and factor 5 in the first quarter in 2021through household income and unemployment. Factor 5 in the 
third quarter of 2020 and factor 3 in the first quarter of 2021were an environmental index, Meanwhile, factor 5 in the fourth quarter (i.e., beds per capital), was the medical supply index, positively affecting MR.

297

Scree Plot

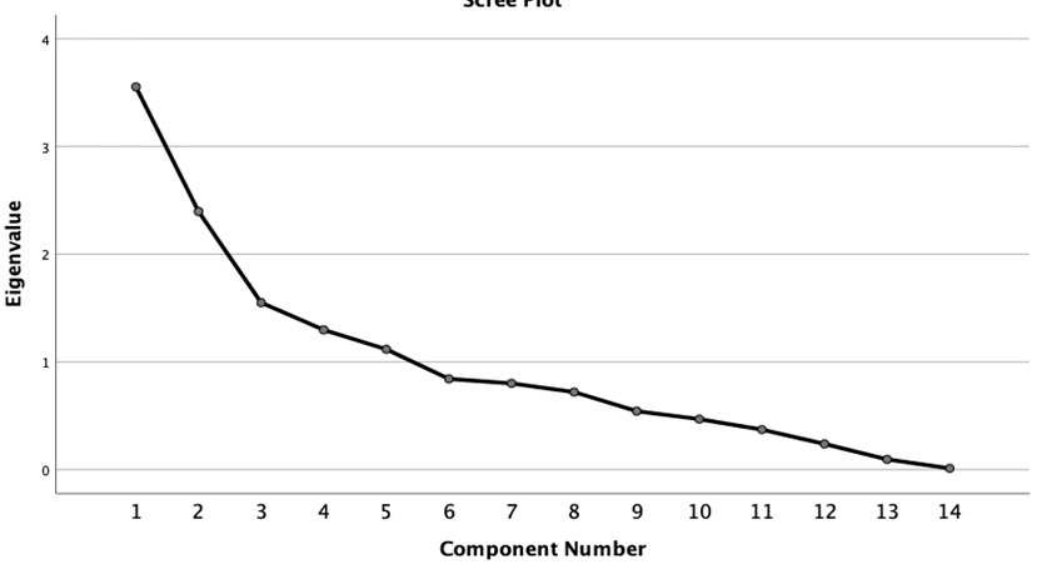

Fig 5. Component factors extracting

Table $5 \quad$ Rotated Component Matrix The Third Quarter Component in 2020 The Fourth Quarter Component in 2020 The first Quarter Component in 2021

\begin{tabular}{lcccccccccccccccccc} 
Itemu & Extr. & 1 & 2 & 3 & 4 & 5 & Extr. & 1 & 2 & 3 & 4 & 5 & Extr. & 1 & 2 & 3 & 4 & 5 \\
\hline TPE & 0.80 & 0.14 & -0.06 & 0.48 & 0.32 & 0.66 & 0.62 & 0.15 & 0.55 & 0.21 & 0.03 & -0.50 & 0.83 & 0.15 & 0.11 & 0.82 & 0.01 & 0.35 \\
\hline PCX & 0.81 & 0.12 & -0.12 & 0.65 & 0.37 & 0.48 & 0.77 & 0.10 & 0.37 & 0.77 & 0.06 & -0.16 & 0.78 & 0.13 & 0.85 & 0.06 & -0.08 & 0.19 \\
\hline AQI & 0.63 & 0.29 & 0.02 & -0.19 & 0.03 & 0.71 & 0.50 & 0.18 & 0.55 & 0.24 & -0.02 & -0.33 & 0.83 & 0.05 & -0.31 & 0.85 & -0.02 & 0.08 \\
\hline THB & 0.95 & 0.97 & 0.06 & 0.01 & -0.02 & -0.01 & 0.96 & 0.97 & 0.01 & 0.02 & 0.08 & 0.04 & 0.96 & 0.98 & 0.02 & -0.02 & 0.06 & -0.02 \\
\hline BPC & 0.34 & 0.15 & 0.04 & 0.05 & 0.08 & -0.56 & 0.64 & 0.12 & 0.00 & 0.09 & -0.05 & 0.79 & 0.33 & 0.11 & -0.08 & -0.54 & 0.08 & 0.13 \\
\hline POD & 0.93 & 0.95 & 0.12 & 0.10 & -0.06 & 0.07 & 0.93 & 0.94 & -0.01 & 0.12 & 0.15 & -0.04 & 0.93 & 0.94 & 0.13 & 0.03 & 0.12 & -0.06 \\
\hline LA & 0.71 & 0.07 & 0.06 & -0.80 & 0.18 & 0.15 & 0.61 & 0.08 & 0.20 & -0.75 & 0.10 & 0.03 & 0.67 & 0.15 & -0.74 & 0.07 & 0.06 & 0.20 \\
\hline PCI & 0.69 & 0.14 & 0.05 & 0.10 & -0.81 & 0.09 & 0.63 & 0.18 & -0.73 & 0.09 & 0.07 & -0.23 & 0.60 & 0.09 & 0.03 & 0.00 & 0.06 & -0.80 \\
\hline IP & 0.97 & 0.98 & 0.08 & 0.02 & -0.03 & 0.06 & 0.97 & 0.98 & 0.01 & 0.03 & 0.11 & -0.02 & 0.97 & 0.98 & 0.03 & 0.02 & 0.09 & -0.03 \\
\hline PBP & 0.59 & 0.29 & 0.27 & 0.51 & 0.31 & -0.26 & 0.71 & 0.23 & 0.26 & 0.70 & 0.23 & 0.22 & 0.69 & 0.26 & 0.65 & -0.18 & 0.25 & 0.31 \\
\hline UEM & 0.68 & 0.03 & 0.00 & 0.13 & 0.80 & 0.14 & 0.65 & 0.00 & 0.81 & 0.07 & 0.01 & -0.06 & 0.68 & 0.03 & 0.12 & 0.20 & 0.01 & 0.79 \\
\hline PMP & 0.36 & -0.14 & 0.53 & -0.16 & 0.01 & -0.17 & 0.45 & -0.16 & -0.02 & -0.08 & 0.46 & 0.46 & 0.39 & -0.16 & -0.16 & -0.23 & 0.54 & 0.04 \\
\hline P39 & 0.79 & 0.19 & 0.84 & 0.20 & -0.10 & 0.08 & 0.78 & 0.17 & -0.08 & 0.17 & 0.84 & -0.03 & 0.79 & 0.18 & 0.18 & 0.09 & 0.84 & -0.12 \\
\hline PSO & 0.65 & -0.21 & -0.77 & 0.05 & -0.03 & -0.02 & 0.69 & -0.19 & -0.03 & 0.05 & -0.81 & 0.03 & 0.64 & -0.21 & 0.03 & 0.01 & -0.77 & -0.02
\end{tabular}

Extraction Method: Principal Component Analysis, Rotation Method: Varimax with Kaiser Normalization, Rotation converged in 6 iterations.

Table 6 The relationship between factors and explanatory variables

$$
\text { Air quality }
$$

study period

Land Area

Economical

and Medical

hospitalization Population

condition

care

\begin{tabular}{llllll}
\hline 2020 Quarter 3 & Factor1 & Factor2 & Factor3 & Factor4 & Factor5 \\
\hline 2020 Quarter 4 & Factor1 & Factor4 & Factor3 & Factor2 & Factor5 \\
\hline 2021 Quarter1 & Factor1 & Factor4 & Factor2 & Factor5 & Factor3 \\
\hline
\end{tabular}




\begin{tabular}{|c|c|c|c|c|c|}
\hline Explanatory Variables & Cor. /Sig. & Cor. /Sig. & Cor. /Sig. & Cor. /Sig. & Cor. /Sig. \\
\hline THB & $0.97 / 0.00$ & & & & \\
\hline POD & $0.95 / 0.00$ & & & & \\
\hline $\mathrm{TP}$ & $0.98 / 0.00$ & & & & \\
\hline \multicolumn{6}{|l|}{ PCN } \\
\hline \multicolumn{6}{|l|}{ PBP } \\
\hline P59 & & $0.84 / 0.00$ & & & \\
\hline P80 & & $-0.77 / 0.00$ & & & \\
\hline \multicolumn{6}{|l|}{ TPE } \\
\hline AQI & & & & & $0.71 / 0.00$ \\
\hline PCI & & & & $-0.81 / 0.00$ & \\
\hline UEM & & & & $0.801 / 0.00$ & \\
\hline BPC & & & & & $0.78 / 0.00$ \\
\hline LA & & & $-0.81 / 0.00$ & & \\
\hline
\end{tabular}

3.6 Comparison of composite OLS and composite GWR models

The OLS regression examines whether there is a linear relationship between cumulative case and its factors, as well as between death rate and its factors. By the T-test and F-test, all factors significant. By binning MR by quarter, an iterative approach of GWR is conducted to examine how the spatial relationship between MR and its factors change over time. Since MR is clustered and an adaptive kernel in GWR models is adopted. The AICc method would choose the bandwidth which minimizes the AICc value - the AICc is the corrected Akaike Information Criterion (it has a correction for small sample sizes). By comparing the results (Table 7), the AICc value is decreased from 875.23 in the OLS model to 851.54 in the GWR in the third quarter of 2020, whereas $\mathrm{R}^{2}$ increased from 0.17 in the OLS model to 0.37 in the GWR models of two quarters. As these two models represent a global and a local approach respectively, the neighbors are declined from 254 neighbors in the OLS models to 128 neighbors in the GWR models. In Q4 2020, the same trend of AICc decrease is observed from 665.44 in the OLS model to 653.85 in the GWR, and $\mathrm{R}^{2}$ increased from 0.10 in the OLS model to 0.20 in the GWR model. In three times, the GWR model enjoyed higher predictive power than OLS and its hence superior. Despite the GWR model remained moderately weak in modeling MR, the models are significant.

Table 7 GWR \& OLS models' Comparison

\begin{tabular}{lcccccc}
\hline \multicolumn{1}{c}{ Item } & \multicolumn{2}{c}{ The Third Quarter of 2020} & \multicolumn{2}{c}{ The Fourth Quarter of 2020} & \multicolumn{2}{c}{ The first Quarter of 2021 } \\
\hline & OLS & GWR & OLS & GWR & OLS & GWR \\
\hline AICc & 875.23 & 851.54 & 665.44 & 653.85 & 875.2 & 851.54 \\
\hline$R^{2}$ & 0.17 & 0.37 & 0.10 & 0.20 & 0.16 & 0.37 \\
\hline Std. Deviation & 0.59 & 0.74 & 0.29 & 0.35 & 0.59 & 0.74 \\
\hline Neighbors & 254 & 128 & 254 & 201 & 254 & 128 \\
\hline Max_Value & -1.52 & -0.57 & -2.78 & -2.93 & -1.52 & -0.57 \\
\hline Min_Value & -5.22 & -4.92 & -5.66 & -4.97 & -5.23 & -4.92 \\
\hline Average & -3.18 & -3.14 & -2.78 & -3.80 & -3.18 & -3.14 \\
\hline
\end{tabular}

3.7 GWR result analysis. 


\subsubsection{Spatial change of MR factors.}

Based on existing research, COVID-19 quarterly GWR models are also implemented in the research area [54-55]. Figure 6 incorporates Texas spatiotemporal distribution maps based on 5 factors in terms of 5 aspects in three quarters.

In the third quarter of 2020, factor 1 among 5 factors is the dominant effect on MR due to the maximum range of coefficient is -0.15 to 0.04 . It is the lowest impact in central Texas thanks to the coefficient range of -2.14 to -1.73 , implying the hospitalization capacity has not been stressed beyond full capacity. Therefore, when looking at Factor 1 in the third quarter, all Texas counties were in the negative range which was good. For Factor 2, a high score reflects more population in 20-59 and less than 80 elderly population. A negative relationship with MR indicates lower mortality in younger population (but also higher mortality in elderly population). This negative relationship was the strongest in northern TX but weakest in western TX. In addition, the negative values do not mean smallest impacts, just representing the relationship. Interestingly, the progression was South-North oriented in the third quarter, but East-West oriented in the fourth quarter. Factor 3 is a natural supply index, having remarkable spatial disparity for its coefficient is from range $-0.52--0.24$ to range $0.3-0.45$. In central Texas, the land area is little driven COVID-19 MR, but it reversely works on South Texas. That indicates spatial distancing is more available for South Texas than central Texas. Factor 4 is an economic composite index that coefficient is from range -0.63--0.48 to range $0.12-0.26$. This is a "bad" economy factor where PCI is negative and UEM is positive. western TX has negative coefficients meaning bad economy didn't result in higher MR, but eastern TX did have positive coefficients which indicates poorer population suffered first. Factor 5 is the air quality index that coefficient is from range $-0.58--0.38$ to range $0.18-0.38$. AQI is higher with poor air quality. If air quality affects MR of COVID-19, it should have a positive relationship (i.e., the worse the air quality, the higher MR). Hence, a negative relationship means air quality didn't matter (regardless of the AQ was good/bad in that area), but there was a positive relationship in W \& Central/E TX (near Harris County) when COVID-19 emerged in Q3.

In the fourth quarter of 2020, factor 1 among 5 factors is not the dominant effect on MR without the range of maximum coefficient is - $0.43--0.12$. That means the hospitalization capacity has not been stressed beyond full capacity. Factor 2 is an economic composite index that coefficient is from range -0.21--0.14 to range 0.13-0.17. The central TX became the divide with neutral relationship in this factor, but western TX remained negative but eastern TX became positive. Factor 3 is a natural supply index that coefficient is from range -0.41-0.31 to range 0.02-0.08. In northern Texas, the land area is little driven COVID-19 MR, but it reversely works on South and West Texas. That indicates spatial distancing is more available for South and West Texas than northern Texas. Factor 4 is adult population index the coefficient is moved from range -0.31--0.29 to range -0.14--0.1. A negative relationship with MR indicates lower mortality in younger pop (but also higher mortality in elderly pop). This negative association was the strongest in South and West TX but weakest in the northern TX. Factor 5 is the medical supply index that coefficient is from range -0.04--0.03 to range 0.21-0.24. Higher BPC was supposed to have lower MR in general. Nevertheless, there were only very few TX counties had slightly negative coefficients, but most in positive. This indicates that by Q4, MR still went up despite higher BPC.

In the first quarter of 2021, Factor 1 that coefficient is from range -2.14--1.73 to range -0.15--0.04 is negative related deaths all across TX based on negative coefficients. Factor 2 becomes positive precipitation and negative Land area, and it is negatively related to death across TX due to negative coefficients. That means the higher the precipitation or less land area, the less death. This is a bit counter-intuitive. Factor 3 that coefficient is from range -0.52--0.24 to range 0 . 3-0.45 is an environmental factor of positive temperature and AQI. A positive relationship death means the higher temp and the poorer air quality caused more death, or colder temperature/better AQI caused less death. A negative relationship is the opposite. It is negative in central to west TX, but positive in the eastern TX. Factor 4 is the adult population. It is all negative in the western TX but positive in the South TX. Factor 5 is the poor economic condition. The positive relationship indicates that the poor economic condition is affecting in the West, South-east, and the central TX.

\subsubsection{Temporal change of CC factors}

Population and hospitalization impact on COVID-19 within 3 quarters is relatively negative. For coefficients, the value of the coefficient is fixed between -2.14 and -0.0 .04 . For the movement of spatial impacts, the spatial distribution 
of COVID-19 impacts is stagnant across three quarters. Due to negative impacts in entire Texas population and hospitalization is not determinant of curbing Texas COVID-19 CC spread. Hence, community containment measures are the crucial result of cluster spreading as one of the characteristics of COVID deterioration.

Adult population impacts are quite a few negative in two quarters of 2020 and positive impact of 2021 the first quarter in terms of two aspects. First, the coefficients from the third quarter to the fourth quarter are still, accounting for -0.74- 0.17 . That means policy restrictions are gradually working and the virus is extremely spreading along with spatial cluster. Second,

Air quality impacts during three quarters are flexible in terms of two aspects. First, the coefficient range in third quarters of is increased from -0.58-0.38 until no exhibition in the fourth quarter. It demonstrated that the role of environments is decreasing. Second, both the areas of positive impacts with red colors and the areas of negative impacts with blue colors are moved from north-west to south-east Texas, from north-central to south-central, respectively. Interestingly, positive air quality impacts are shown in the first quarter of 2021. It implies that environmental impacts are still working and accelerate COVID-19 spreading.

Economic impacts during three quarters are remarkable but are the most important factors among the 5 factors. On one hand, the coefficient range in three quarters is increased gradually from -0.63-0.48 to 0.18-0.77. It demonstrated that the role of economic impacts is rising with COVID-19 case growth. Second, the areas of positive impacts with red colors are increasing surround east Texas, whereas the areas of negative impacts with blue colors are extending around west Texas.

Natural supply impacts in three quarters have fluctuated. First, the coefficient range within three quarters is changed from $-0.52-0.24$ into $-0.19-0.04$. It demonstrated that the role of natural supply is barely noticed. Second, natural supply has few impacts on COVID-19 expansions.

Medical supply impacts in three quarters have fluctuated as well. First, it is noticed that there was no representation of medical supply index in the third quarter, and it triggered in the fourth quarter. Its coefficient range is changed -0.04-0.03 into 0.21-0.24. It demonstrated that the role of medical supply impacts is increasing and out of control. Second, the cluster of positive impacts with red colors is in east Texas. Notably, medical supple impacts are temporary results from no emerging in the first quarter of 2021.

Fig 6 Spatial-temporal GWR Map

\begin{tabular}{|l|l|l|l|}
\hline Factor & $\begin{array}{l}\text { The Third Quarter GWR } \\
\text { Map in 2020 }\end{array}$ & $\begin{array}{l}\text { The Fourth Quarter GWR } \\
\text { Map in 2020 }\end{array}$ & $\begin{array}{l}\text { The Fourth Quarter GWR } \\
\text { Map in 2021 }\end{array}$ \\
\hline $\begin{array}{l}\text { Population \& Hospi- } \\
\text { talization }\end{array}$ & $\begin{array}{l}\text { Population \& Hospitalization } \\
\text { Population \& Hospitalization }\end{array}$ & Population \& Hospitalization \\
\hline & &
\end{tabular}




\begin{tabular}{|c|c|c|c|}
\hline Adult Population & 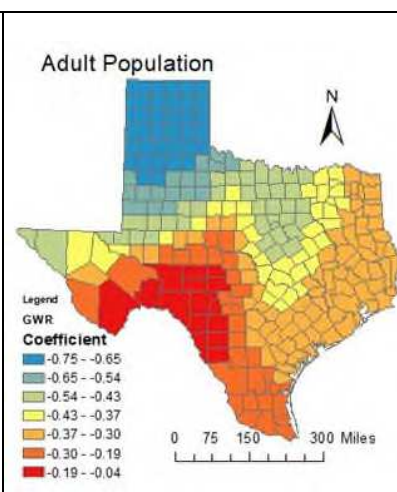 & 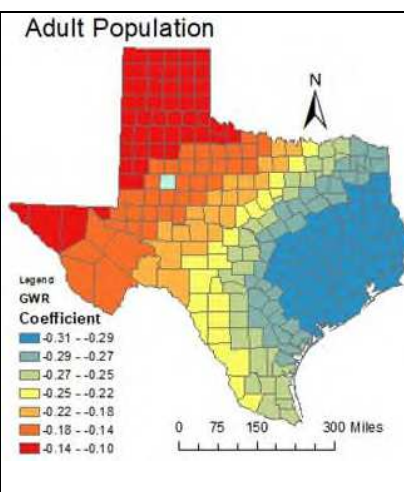 & 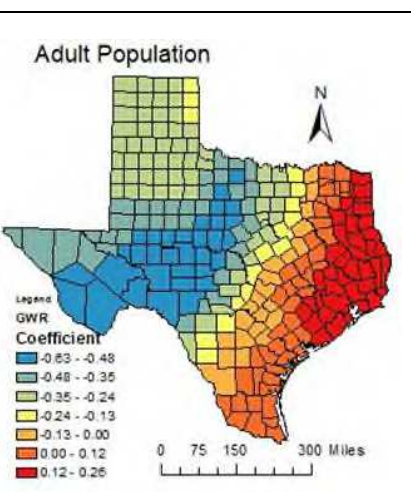 \\
\hline Land Area & 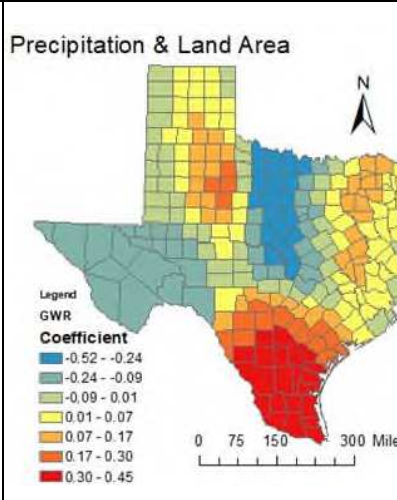 & 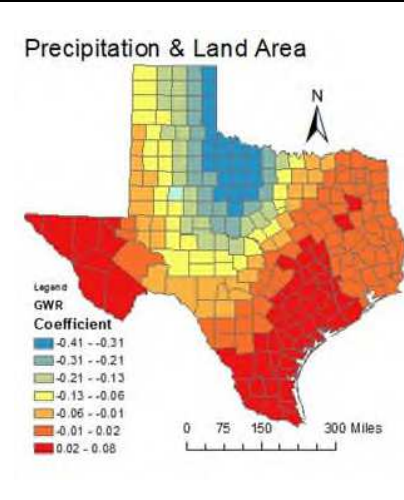 & 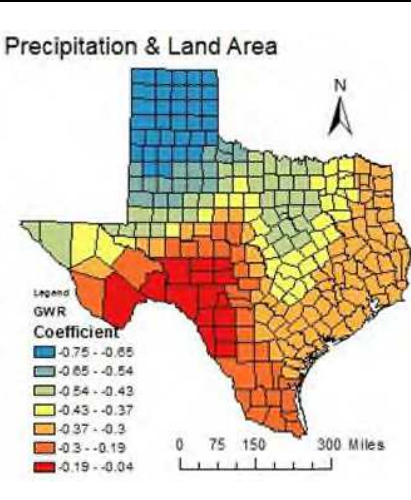 \\
\hline $\begin{array}{l}\text { Economical- } \\
\text { Condition }\end{array}$ & 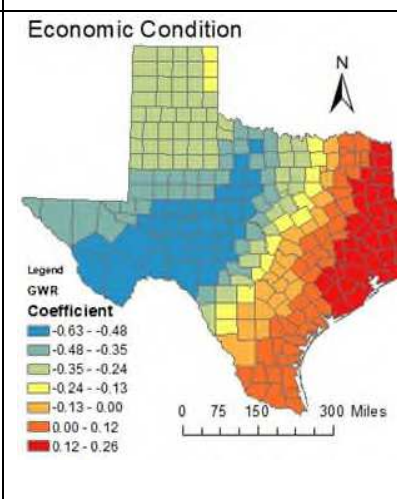 & 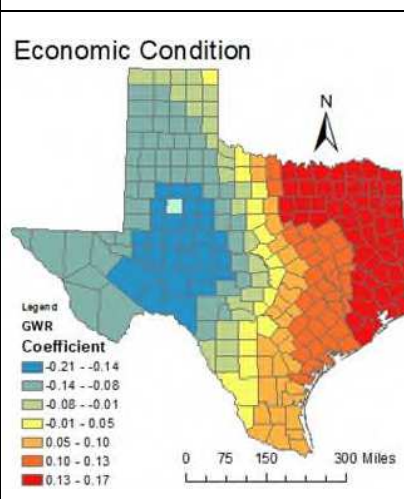 & 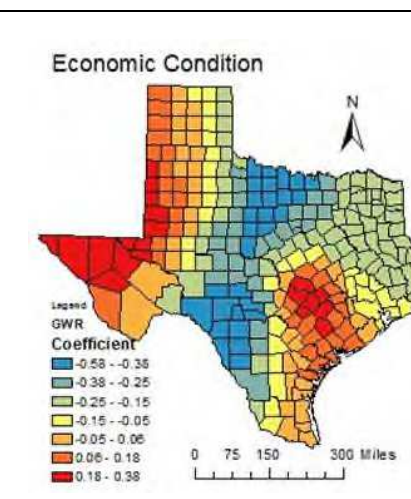 \\
\hline $\begin{array}{l}\text { Air Quality in } \\
\text { Q3 and Q1 but } \\
\text { Medical Sup- } \\
\text { ply in Q4 }\end{array}$ & 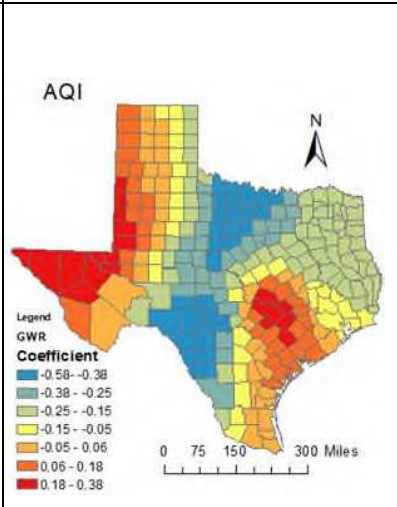 & 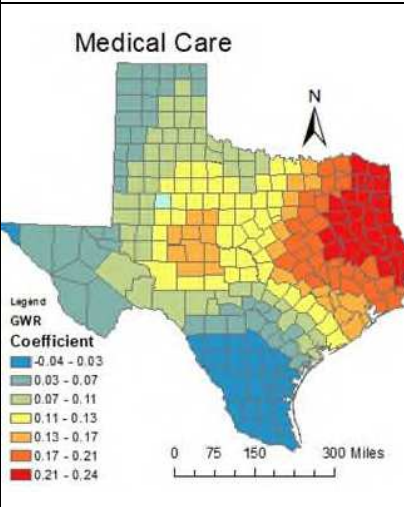 & 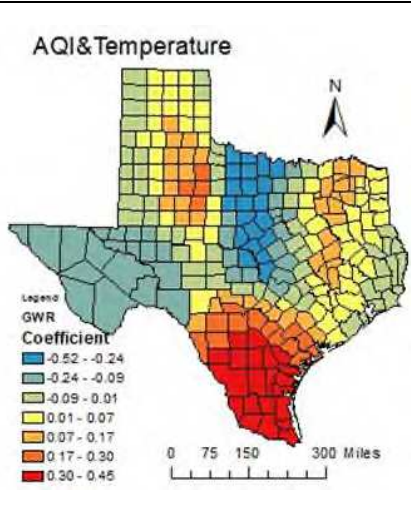 \\
\hline
\end{tabular}


COVID-19 virus runs rampant in high-density housing sites such as nursing homes. Emergent cluster detection is a precise way of tracking the virus. In this study, we explored three types of clustering analysis methods. A spacetime cluster's detection of COVID-19 mortality rate is built on Kulldorff's scan statistic method, which is the most popular in the epidemiology application. What we did first is to test the null hypothesis H0 (constant probability for all areas) and the alternative hypotheses H1(the specific area $\mathrm{z}$ has a larger probability than outside areas) using a Poisson model. Then we calculated the maximum likelihood and p-value, based on a given region $z$. Two clusters were pointed out that the sensitive period was July-September and November 2020-February,2021, referring to 199 counties. To narrow the tracking area, we used EM and HC clustering to further seek much better clusters. EM algorithm assists in finding out seven smaller clusters in the last quarter. HC clustering analysis directly pinpointed eight counties as a significant cluster. In fact, if the COVID-19 case data were available at street or neighborhood level, meaning the address of individual death could be better captured, specific hotspot of neighborhood or even building could be identified via GIS. HC and EM clustering provide richer descriptions of clustering structures than traditional cluster detections. Importantly, they facilitate the realization of tracing the trajectory of individual cases based on reality. For example, there is a death case at Pioneer Lodge Motel in Zion National Park in Hays county in Texas. We use ST_Buffer to build a 100meter quarantine area around the building of Pioneer Lodge in PostGIS software in Fig 6. Next, the intersection area is selected around Pioneer Lodge Motel in Zion National Park. Finally, it is easy to use ST_Area command to find out 10 of the biggest building at the intersection area. The blue squares are identified as suspected buildings with high-density connections. Due to confidential COVID_19 patient information, our research does not incorporate patient addresses. The below figure aims to explain the possibility of the implementation of tracking the virus based on geographical cluster detection.

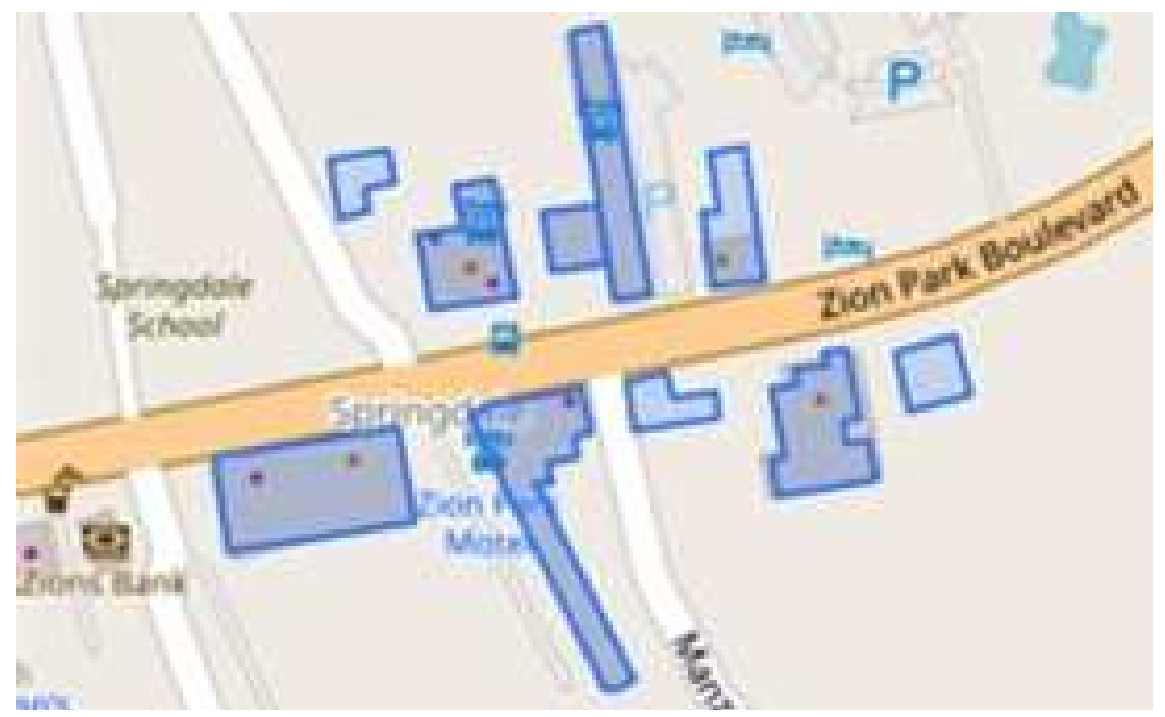

Fig 7. Tracing Map of Pioneer Lodge Motel

The purpose of GWR modeling is to find out related COVID-19 factors. That is not only because the source of COVID-19 is still a puzzle, but also because there may be a causality hidden within the correlation. In the GWR model, COVID-19 mortality rate analysis, the research period is locked at the last two quarters in 2020 according to the previous clustering analysis. we examined the inclusion of race, temperature, air quality, precipitation, hospitalization, age structure 14 variables. Furthermore, the principal component analysis (PCA) has integrated five factors related to mortality rate, including total population and hospitalization, medical supply, age structure, air quality, and economic condition. Explanatory variables are highly significant to the corresponding factors as well in Table 6. Lastly, by defining a weight as the variance proportions for each variable, the GWR model disclosures sensitive factors in spatial-temporal variability of COVID-19 mortality rates in response to social-economic and environmental impacts in Texas counties. AQI, economic condition, and adult population indexes are regarded as sensitive factors.

Since time series are too short to be enough considered, spatial-temporal cluster detection, EM and HC clustering detection, and GWR modeling were explored to examine the imbalanced distribution of COVID-19 MR and the complex relationship with its risk factors [57]. The longitudinal monitor mechanism filled the gap of geographical analysis of 
COVID-19. This study has conducted some spatiotemporal analysis that provides unique insights about COVID-19. It is a mix of conventional Geographical Information Systems (GIS) with the use of modeling and simulation skills [58].

The sensitive area is different in clustering analysis and GWR modeling due to different distribution. In cluster analysis, the sensitive areas are located at Cottle, Stonewall, Bexar, Tarrant, Dallas, Harris, Jim hogg, and Real eight counties, corresponding to south-east Texas. Their distinction is from different mathematical distributions. Clustering methods are used by Poisson regression analysis while Gaussian distribution is applied in GRW modeling. In spatial epidemiology, mortality using a Poisson process is more appropriate than a linear scale, which the GWR is. Specifically, the Poisson regression identifies the relative risk of mortality linked with a given exposure that can represent a risk rise with some percent. Thus, clustering detection is more accurate than GWR in the forecast of mortality region [59].

Referring back to the current study, the first strength is that its performance geographically targeted ways to blunt the spread of COVID-19 as quickly as possible and save lives. Through the comparison between objective clustering techniques and traditional space-time cluster detection, we achieve an improved cluster solution. HC algorithm clustering method tracked one cluster with eight counties in the last quarter and one cluster with four counties in the third quarter, EM clustering analysis captured seven clusters in the last quarter and no cluster in the third quarter, instead of two large scale clusters in the space-time cluster methods. The second strength is the possibility of modeling GWR on the PCA outcomes, which improved the robustness of findings based on OLS results. Furthermore, the combination of clustering analysis and Postgre application can provide instant information that helps decision-makers and public health professionals to take immediate action to inhibit current disease spread and to save lives in the future. In addition, quick position determination can blunt the avenue of the virus spreading and save resources (time and lives).

This research just focuses on the Texas Covid-19 scenario, the application of research cannot extrapolate to other states. We didn't capture chronic disease data to supports this research. As explanatory variables, they should be incorporated in future studies, although are excited to see clinical characteristics [62] and cardiovascular conditions impacts on COVID-19 health outcomes [63]. Collecting data of multiple dimensions might improve and enrich spatial variability findings of COVID-19. This research merely intended to spatial-temporal quarterly GWR models, yet there is a distance to be reached for daily dynamic GWR models. GTWR or more effective spatial-temporal models should be further researched in the future. COVID-19 virus spreading relies on intangible person's mobility and social activities [64]. Due to dynamic and complicated people's behavior, this research is fragmentation in the constantly dynamic mobility, and traced people's trajectory with stationary geographical location. Clustering analysis is not only limited to the geographical field but also should be reached in other fields such as biological subjects. For instance, a multiple sequence alignment is explored by clustering analysis, rather than using clustalW2 tools, which aims to DNA or protein multiple sequence alignment program for proteins [65].

\subsection{Implications}

The COVID-19 pandemic revealed systemic flaws in the health distribution system and American multiculturalism. It also exposed the weakness of conservative liberalism in the U.S, which is hard to unify ideology in social crisis and flourish in a consistent manner [61]. This research will benefit geographical health divides evenly and provide medical service references transparently. Inspired by [58,60], who applied and compared the performance of multiscale GWR models across the United States for incident rates and death rates to account for the spatial variability of COVID-19, spatial-temporal GWR models are considered to compare the global OLS model to disclosure different change of COVID-19 cumulative case in response to social-economic and environmental variables at county-level in Texas. To add spatial-temporal variability understanding of empirical COVID-19 analysis, the GWR modeling was considered on space-time detection of an emerging cluster of COVID-19 MR. Therefore, the results of this study provide new empirical evidence to support future geographic modeling of the diseases.

Space-time cluster detection, HC\&EM clustering analysis, and spatial-temporal geographical weighted regression modeling of COVID-19 are crucial to improve the surveillance health system and enhancing recognition of emergency preparedness plans for local hospital. They are beneficial for the government of Texas and CDC to make appropriate 
and scientific judgments, target vulnerable communities, distribute health care, improve disease surveillance and response systems [66-67]. Notwithstanding, COVID-19 is like a justice scale to measure each country's execution, COVID-19 vaccine is the best way to eliminate COVID-19 death.

\section{Declaration}

Ethics approval and consent to participate: Not applicable.

Consent for publication: Not applicable.

Availability of data and materials: The datasets used and analyzed during the current study are available from the corresponding author on reasonable request.

Competing interests: Authors declare no conflict of interest.

Funding: This research received no external funding.

Author Contributions: Conceptualization and methodology, Xiu.Wu., and Jinting.Zhang.; investigation, resources, and data curation, Xiu.Wu.; writing - original draft preparation, Xiu.Wu.; writing - review and editing, Jinting.Zhang.; supervision and project administration, Edwin T Chow.

Acknowledgments: I would like to extend my sincere gratitude GIS instructor, Dr. T. Edwin Chow, for his instructive advice and useful suggestions on this paper.

\section{References}

1. Yüksel Peker, Yeliz Celik, Semih Arbatli, Sacide Rana Isik, Baran Balcan, Ferhan Karataş, Fatma Işıl Uzel, Levent Tabak, Betül Çetin, Arzu Baygül, Ayşe Bilge Öztürk, Elif Altuğ, Sinem İliaz, Cetin Atasoy, Mahir Kapmaz, Duygu Yazici, Hasan Bayram, Birsen Durmaz Çetin, Benan Çağlayan. (2021) Effect of High-Risk Obstructive Sleep Apnea on Clinical Outcomes in Adults with Coronavirus Disease 2019: A Multicenter, Prospective, Observational Cohort Study. Annals of the American Thoracic Society 0:ja. Online publication date: 17-Feb-2021.

2. Ahmar, Ansari Saleh, and Eva Boj. 2020. "Will COVID-19 Confirmed Cases in the USA Reach 3 Million? A Forecasting Approach by Using SutteARIMA Method." Current Research in Behavioral Sciences 1 (November). doi:10.1016/j.crbeha.2020.100002.

3. Bashir, Muhammad Farhan, Benjiang MA, and Luqman Shahzad. 2020. “A Brief Review of Socio-Economic and Environmental Impact of Covid-19." Air Quality, Atmosphere \& Health: An International Journal 13 (12): 1403. doi:10.1007/s11869-02000894-8.

4. Woolhandler, Steffie, David U Himmelstein, Sameer Ahmed, Zinzi Bailey, Mary T Bassett, Michael Bird, Jacob Bor, et al. 2021. “Public Policy and Health in the Trump Era." The Lancet 397 (10275): 705-53. doi:10.1016/S0140-6736(20)32545-9.

5. Center for Systems Science and Engineering, John Hopkins University. COVID-19 Data Repository. 2020. https://coronavirus. jhu.edu/map.html (accessed Dec 29, 2020)

6. Holshue, Michelle L., Chas DeBolt, Scott Lindquist, Kathy H. Lofy, John Wiesman, Hollianne Bruce, Christopher Spitters, et al. 2020. "First Case of 2019 Novel Coronavirus in the United States." New England Journal of Medicine 382 (10): $929-36$. doi:10.1056/NEJMoa2001191. (p.?)

7. M. Kulldorff. A spatial scan statistic. Communications in Statistics - Theory and Methods, 26 (6) (1997), pp. 1481-1496

8. Desjardins, M.R. ( 1 ), A. ( 2 ) Hohl, and E.M. ( 3 ) Delmelle. 2021. "Rapid Surveillance of COVID-19 in the United States Using a Prospective Space-Time Scan Statistic: Detecting and Evaluating Emerging Clusters." Applied Geography 118. Accessed March 13. doi:10.1016/j.apgeog.2020.102202.

9. Hohl, Alexander, Eric M. Delmelle, Michael R. Desjardins, and Yu Lan. 2020. "Daily Surveillance of COVID-19 Using the Prospective Space-Time Scan Statistic in the United States." Spatial and Spatio-Temporal Epidemiology 34 (August). doi:10.1016/j.sste.2020.100354.

10. Raid Amin, Terri Hall, Jacob Church, Daniela Schlierf, Martin Kulldorff. Geographical surveillance of COVID-19: Diagnosed cases and death in the United States. Cold Spring Harbor Laboratory Press doi: https://doi.org/10.1101/2020.05.22.20110155 
11. Rosenkrantz, L. (1), N. (1) Schuurman, N. (2) Bell, and O. (3) Amram. 2021. "The Need for GIS Science in Mapping COVID19." Health and Place. Accessed January 16. doi:10.1016/j.healthplace.2020.102389.

12. Smith, Charlotte D, and Jeremy Mennis. 2020. "Incorporating Geographic Information Science and Technology in Response to the COVID-19 Pandemic." Preventing Chronic Disease 17 (July): E58. doi:10.5888/pcd17.200246.

13. Sun, Yeran, Xuke Hu, and Jing Xie. 2021. "Spatial Inequalities of COVID-19 Mortality Rate in Relation to Socioeconomic and Environmental Factors across England." Science of the Total Environment 758 (March). doi: 10.1016/j.scitotenv.2020.143595.

14. Scarpone, Christopher, Sebastian T Brinkmann, Tim Große, Daniel Sonnenwald, Martin Fuchs, and Blake Byron Walker. 2020. "A Multimethod Approach for County-Scale Geospatial Analysis of Emerging Infectious Diseases: A Cross-Sectional Case Study of COVID-19 Incidence in Germany." International Journal of Health Geographics 19 (1): 32. doi:10.1186/s12942-020-002251.

15. Caraka, R.E., Y. Lee, R.C. Chen, T. Toharudin, P.U. Gio, R. Kurniawan, and B. Pardamean. 2021. “Cluster Around Latent Variable for Vulnerability Towards Natural Hazards, Non-Natural Hazards, Social Hazards in West Papua." IEEE Access, Access, IEEE 9 (January): 1972-86. doi:10.1109/ACCESS.2020.3038883.

16. Tate, Eric, Md Asif Rahman, Christopher T. Emrich, and Christopher C. Sampson. 2021. "Flood Exposure and Social Vulnerability in the United States." Natural Hazards, 1. doi:10.1007/s11069-020-04470-2.

17. Cumberbatch, Janice, Crystal Drakes, Tara Mackey, Mohammad Nagdee, Jehroum Wood, Anna Karima Degia, and Catrina Hinds. 2020. "Social Vulnerability Index: Barbados - A Case Study." Coastal Management 48 (5): $505-26$. doi:10.1080/08920753.2020.1796193.

18. Mollalo, A., Vahedi, B., \& Rivera, K. M. (2020). GIS-based spatial modeling of COVID-19 incidence rate in the continental United States. Science of the Total Environment, 728. https://doiorg.libproxy.txstate.edu/10.1016/j.scitotenv.

19. Kim, L., Whitake, M., O'Halloran, A., Kambhampati, A., Chai, S. J., Reingold, A., Armistead, I., Kawasaki, B., Meek, J., YouseyHindes, K., Anderson, E. J., Openo, K. P., Weigel, A., Ryan, P., Monroe, M. L., Fox, K., Kim, S., Lynfield, R., Bye, E., \& Davis, S. S. (2020). Hospitalization Rates and Characteristics of Children Aged $<18$ Years Hospitalized with Laboratory-Confirmed COVID-19 - COVID-NET, 14 States, March 1-July 25, 2020. MMWR: Morbidity E Mortality Weekly Report, 69(32), 1081-1088. https://doi-org.libproxy.txstate.edu/10.15585/mmwr.mm6932e3

20. Bashir A, Malik AW, Rahman AU, Iqbal S, Cleary PR, Ikram A. MedCloud: Cloud-Based Disease Surveillance and Information Management System. IEEE Access, Access, IEEE. 2020;8:81271-81282. doi:10.1109/ACCESS.2020.2990967

21. Sha, D., Malarvizhi, A.S., Liu, Q., Tian, Y., Zhou, Y., Ruan, S., Dong, R., Carte, K., Lan, H., Wang, Z. and Yang, C., 2020. A State-Level Socioeconomic Data Collection of the United States for COVID-19 Research. Data, 5(4), p.118

22. Suman Chakraborti, Arabinda Maiti, Suvamoy Pramanik, Srikanta Sannigrahi, Francesco Pilla, Anushna Banerjee, and D. N. Das. 2021. "Evaluating the Plausible Application of Advanced Machine Learnings in Exploring Determinant Factors of Present Pandemic: A Case for Continent Specific COVID-19 Analysis." Science of the Total Environment 765. doi:https://www-sciencedirect-com./science/article/abs/pii/S0048969720362525.

23. Rodriguez-Villamizar, Laura A., Luis Carlos Belalcázar-Ceron, Julián Alfredo Fernández-Niño, Diana Marcela Marín-Pineda, Oscar Alberto Rojas-Sánchez, Lizbeth Alexandra Acuña-Merchán, Nathaly Ramírez-García, et al. 2021. “Air Pollution, Sociodemographic and Health Conditions Effects on COVID-19 Mortality in Colombia: An Ecological Study." Science of the Total Environment 756 (February). doi:10.1016/j.scitotenv.2020.144020.

24. Perkin, M. R., Heap, S., Crerar-Gilbert, A., Albuquerque, W., Haywood, S., Avila, Z., Hartopp, R., Ball, J., Hutt, K., \& Kennea, N. (2020). Deaths in people from Black, Asian, and minority ethnic communities from both COVID-19 and non-COVID causes in the first weeks of the pandemic in London: a hospital case note review. BMJ Open, 10(10), e040638. https://doi-org.libproxy.txstate.edu/10.1136/bmjopen-2020-040638

25. Nguyen, L. H., Drew, D. A., Graham, M. S., Joshi, A. D., Guo, C.-G., Ma, W., Mehta, R. S., Warner, E. T., Sikavi, D. R., Lo, C.-H., Kwon, S., Song, M., Mucci, L. A., Stampfer, M. J., Willett, W. C., Eliassen, A. H., Hart, J. E., Chavarro, J. E., Rich-Edwards, J. W., ... Chan, A. T. (2020). Risk of COVID-19 among front-line health-care workers and the general community: a prospective cohort study. The Lancet. Public Health, 5(9), e475-e483. https://doi-org.libproxy.txstate.edu/10.1016/S2468-2667(20)30164-X

26. Rothstein, A., Oldridge, O., Schwennesen, H., Do, D., \& Cucchiara, B. L. (2020). Acute Cerebrovascular Events in Hospitalized COVID-19 Patients. Stroke (00392499), 51(9), e219-e222. https://doi-org.libproxy.txstate.edu/10.1161/STROKEAHA.120.030995

27. Caraballo, C., McCullough, M., Fuery, M. A., Chouairi, F., Keating, C., Ravindra, N. G., Miller, P. E., Malinis, M., Kashyap, N., Hsiao, A., Wilson, F. P., Curtis, J. P., Grant, M., Velazquez, E. J., Desai, N. R., \& Ahmad, T. (2020). COVID-19 infections and outcomes in a live registry of heart failure patients across an integrated health care system. PloS One, 15(9), e0238829. https://doiorg.libproxy.txstate.edu/10.1371/journal.pone.0238829

28. Majidi, S., Fifi, J. T., Ladner, T. R., Lara-Reyna, J., Yaeger, K. A., Yim, B., Dangayach, N., Oxley, T. J., Shigematsu, T., Kummer, B. R., Stein, L. K., Weinberger, J., Fara, M. G., De Leacy, R., Dhamoon, M. S., Tuhrim, S., \& Mocco, J. (2020). Emergent Large 
Vessel Occlusion Stroke During New York City's COVID-19 Outbreak: Clinical Characteristics and Paraclinical Findings. Stroke (00392499), 51(9), 2656-2663. https://doi-org.libproxy.txstate.edu/10.1161/STROKEAHA.120.030397

29. Lakhani, A. (2020). Which Melbourne Metropolitan Areas Are Vulnerable to COVID-19 Based on Age, Disability, and Access to Health Services? Using Spatial Analysis to Identify Service Gaps and Inform Delivery. Journal of Pain and Symptom Management, 60(1), e41-e44. https://doi-org.libproxy.txstate.edu/10.1016/j.jpainsymman.2020.03.041

30. Bhayani, S., Sengupta, R., Markossian, T., Tootooni, S., Luke, A., Shoham, D., Cooper, R., \& Kramer, H. (n.d.). Dialysis, COVID19, Poverty, and Race in Greater Chicago: An Ecological Analysis. Kidney Medicine, 2(5), 552-558.e1. https://doi-org.libproxy.txstate.edu/10.1016/j.xkme.2020.06.005

31. Hawkins, D. (n.d.). Differential occupational risk for COVID-19 and other infection exposure according to race and ethnicity. American Journal of Industrial Medicine, 63(9), 817-820. https://doi-org.libproxy.txstate.edu/10.1002/ajim.23145

32. Patel, A. P. ( 1,2,3 ), Khera, A. V. ( 1,2,3 ), Paranjpe, M. D. ( 2,3 ), Kathiresan, N. P. ( 3,4 ), \& Rivas, M. A. ( 5 ). (n.d.). Race, socioeconomic deprivation, and hospitalization for COVID-19 in English participants of a national biobank. International Journal for Equity in Health, 19(1). https://doi-org.libproxy.txstate.edu/10.1186/s12939-020-01227-y

33. Jones, J. ( 1 ), Sullivan, P. S. ( 1 ), Sanchez, T. H. ( 1 ), Guest, J. L. ( 1 ), Hall, E. W. ( 1 ), Luisi, N. ( 1 ), Zlotorzynska, M. ( 1 ), Wilde, G. ( 2 ), Siegler, A. J. ( 2 ), \& Bradley, H. ( 3 ). (n.d.). Similarities and differences in COVID-19 awareness, concern, and symptoms by race and ethnicity in the United States: Cross-sectional survey. Journal of Medical Internet Research, 22(7). https://doi-org.libproxy.txstate.edu/10.2196/20001

34. Khazanchi R( 1,2), Evans CT( 3,4 ), Marcelin JR( 5 ). Racism, Not Race, Drives Inequity Across the COVID-19 Continuum. JAMA network open. 3(9):e2019933. doi:10.1001/jamanetworkopen.2020.19933

35. Rentsch, C.T. ( 1,2 ), F. ( 1,3 ) Kidwai-Khan, J.P. ( 1,3 ) Tate, J.T. ( 1,5 ) King, M. ( 1 ) Skanderson, R.G. ( 1,6 ) Hauser, K.M. ( 1,3 ) Akgün, et al. "Patterns of COVID-19 Testing and Mortality by Race and Ethnicity among United States Veterans: A Nationwide Cohort Study." PLoS Medicine 17, no. 9. Accessed January 16, 2021. doi: 10.1371/journal.pmed.1003379.

36. Liu Q( 1,2 ), Sha D( 1,2 ), Liu W( 1,3 ), et al. Spatiotemporal patterns of COVID-19 impact on human activities and environment in Mainland China using nighttime light and air quality data. Remote Sensing. 12(10). doi:10.3390/rs12101576

37. Hernandez, W., Mendez, A., Zalakeviciute, R., \& Diaz-Marquez, A. M. (2020). Analysis of the Information Obtained From PM2.5 Concentration Measurements in an Urban Park. IEEE Transactions on Instrumentation and Measurement, Instrumentation and Measurement, IEEE Transactions on, IEEE Trans. Instrum. Meas, 69(9), 6296-6311. https://doi-org.libproxy.txstate.edu/10.1109/TIM.2020.2966360

38. Zhang, H., Li, Z., Liu, Y., Xinag, P., Cui, X., Ye, H., Hu, B., \& Lou, L. (2018). Physical and chemical characteristics of PM2.5 and its toxicity to human bronchial cells BEAS-2B in the winter and summer. Journal of Zhejiang University-SCIENCE B: Biomedicine $\mathcal{E}$ Biotechnology, 19(4), 317. https://doi-org.libproxy.txstate.edu/10.1631/jzus.b1700123

39. Xu Y, Liu H, Duan Z. A novel hybrid model for multi-step daily AQI forecasting driven by air pollution big data. Air Quality, Atmosphere E Health: An International Journal. 2020;13(2):197. doi:10.1007/s11869-020-00795-w

40. Wang Z, Chen L, Zhu J, Chen H, Yuan H. Double decomposition and optimal combination ensemble learning approach for interval-valued AQI forecasting using streaming data. Environmental Science and Pollution Research. 2020;27(30):37802. doi:10.1007/s11356-020-09891-x

41. Zhang, X.-T., Liu, X.-H., Su, C.-W., \& Umar, M. (2020). Does asymmetric persistence in convergence of the air quality index (AQI) exist in China? Environmental Science and Pollution Research, 27(29), $36541 . \quad \underline{\text { https://doi-org.lib- }}$ proxy.txstate.edu/10.1007/s11356-020-09498-2

42. Wen S, Kedem B: A semiparametric cluster detection method - a comprehensive power comparison with Kulldorff's method. International Journal of Health Geographics 2009, 8:73-89

43. Dwass D: Modified randomization tests for nonparametric hypotheses. Annuals of Mathematical Statistics 1957, 28:181-187

44. Turnbull BW, Wano EJ, Burnett WS, Howe HL, Clark LC: Monitoring for clusters of disease: application to leukemia incidence in upstate New York. American Journal of Epidemiology 1990, 132:136-143.

45. Yao, Z. J., Tang, J. M. and Zhan, F. B. (2011) 'Detection of arbitrarily-shaped clusters using a neighbor-

Expanding approach: a case study on murine typhus in South Texas, International Journal of Health Geographics, 10(23), p.

(31 March 2011). doi: http://www.ij-healthgeographics.com/content/10/1/23.

46. Wu, C., Steinbauer, J. R., \& Kuo, G. M. (n.d.). EM clustering analysis of diabetes patients basic diagnosis index. AMIA ... Annual Symposium Proceedings / AMIA Symposium. AMIA Symposium, 1158. 
48. Bilginol, K., Denli, H. H., \& Şeker, D. Z. (2015). Ordinary Least Squares Regression Method Approach for Site

Selection of Automated Teller Machines (ATMs). Procedia Environmental Sciences, 26, 66-69. https://doiorg.libproxy.txstate.edu/10.1016/j.proenv.2015.05.026

49. Guidolin, M., \& Pedio, M. (2020). Forecasting commodity futures returns with stepwise regressions: Do commodity-specifical factors help? Annals of Operations Research, https://doi-org.libproxy.txstate.edu/10.1007/s10479-020-03515-w

50. Kutela, Boniphace, Norris Novat, and Neema Langa. 2021. “Exploring Geographical Distribution of Transportation Research Themes Related to COVID-19 Using Text Network Approach." Sustainable Cities and Society 67 (April). doi:10.1016/j.scs.2021.102729.

51. Smith, G. Step away from stepwise. J Big Data 5, 32 (2018). https://doi.org/10.1186/s40537-018-0143-6

52. Wang, J., Wang, S., \& Li, S. (2019). Examining the spatially varying effects of factors on PM2.5 concentrations in Chinese cities using geographically weighted regression modeling. Environmental Pollution, 248, 792-803. $\underline{\text { https://doi- }}$ org.libproxy.txstate.edu/10.1016/j.envpol.2019.02.081

53. Das, S., Avelar, R., Dixon, K., \& Sun, X. (2017). Investigation on the wrong way driving crash patterns using multiple correspondence analysis. https://doi.org/10.1016/j.aap.2017.11.016

54. Tobler, W. R., 1970. A computer movie simulating urban growth in the Detroit region. Econ. Geogr. 46, 234240.

55. Fotheringham, A.S., Charlton. M.E., 2002. Geographically Weighted Regression: The Analysis of Spatially Varying Relationships. Wiley. New York. Chris Brunsdon.

56. Nakaya, T., (2016). GWR4.09 User Manual. Pp. 2-27.

57. Liu, Q., Sha, D., Liu, W., Houser, P., Zhang, L., Hou, R., Lan, H., Flynn, C., Lu, M., Hu, T., \& Yang, C. (2020). Spatiotemporal Patterns of COVID-19 Impact on Human Activities and Environment in Mainland China Using Nighttime Light and Air Quality data. Remote Sensing, 12(10), 1576. https://doi-org.libproxy.txstate.edu/10.3390/rs12101576

58. Mollalo, A., Vahedi, B., \& Rivera, K. M. (2020). GIS-based spatial modeling of COVID-19 incidence rate in the continental United States. Science of the Total Environment, 728.

https://doiorg.libproxy.txstate.edu/10.1016/j.scitotenv.

59. Dockery, D. W., \& Pope, C. A. (1994). Acute Respiratory Effects of Particulate Air Pollution. Annual Review of Public Health, 15(1), 107-132.

60. Luo Y, Yan J, McClure S. Distribution of the environmental and socioeconomic risk factors on COVID19 death rate across continental USA: a spatial nonlinear analysis. Environmental Science and

Pollution Research. 2021;28(6):6587. doi:10.1007/s11356-020-10962-2

61. McNeil, L. M., \& Kelso, T. S. (2013). Spatial temporal information systems : an ontological approach using STK@. CRC Press.

62. Hu Jijia, Zhang YingAng, Wang Wei, Tao ZhiHe, Tian Juan, Shao Ning, Liu Nian, Wei Hui, and Huang Hao. 2021. “Clinical Characteristics of 14 COVID-19 Deaths in Tianmen, China: A Single-Center Retrospective Study." BMC Infectious Diseases 21 (88). doi:https://link-springer-com.libproxy.txstate.edu/article/10.1186/s12879-021-05770-z.

63. Du, H., Wang, D. W., \& Chen, C. (2020). The potential effects of DPP-4 inhibitors on cardiovascular system in

COVID-19 patients. Journal of Cellular \& Molecular Medicine, 24(18), 10274-10278.

https://doi-org.libproxy.txstate.edu/10.1111/jemm.15674

64. Dyson, Kenneth. 2021. Conservative Liberalism in American and British Political Economy. Oxford: Oxford University Press. doi:10.1093/oso/9780198854289.003.0010. 
65. Kalpesh Anjaria. 2012. Phylogenetic analysis of some leguminous trees using CLUSTALW2 bioinformatics tool. 2012 IEEE

66. Gadicherla S, Krishnappa L, Madhuri B, et al. Envisioning a learning surveillance system for 


\section{Figures}

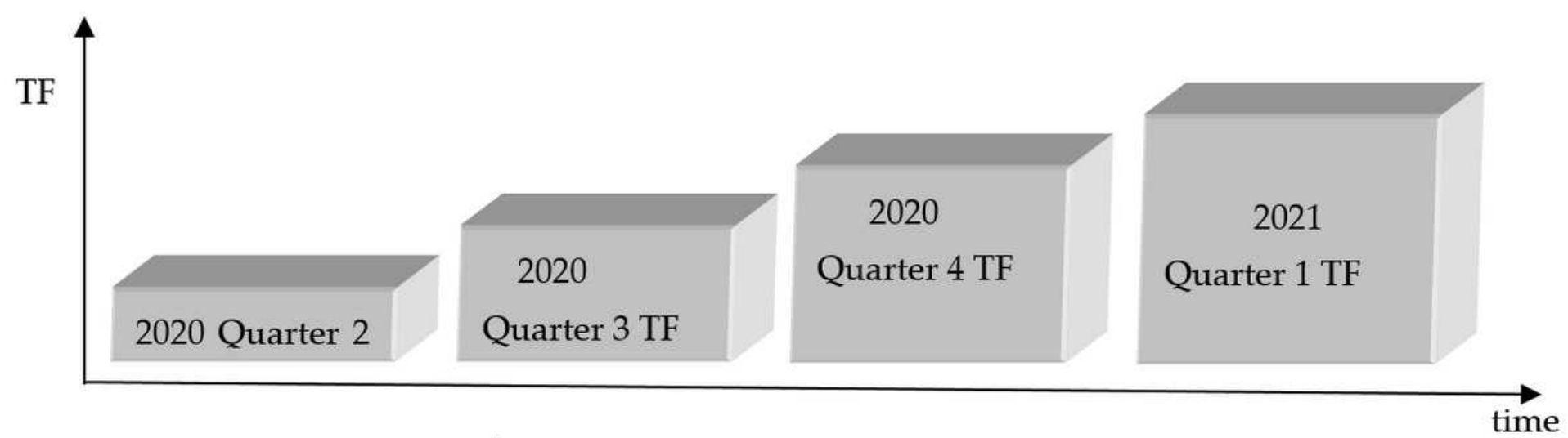

Figure 1

Temporal-Study Framework

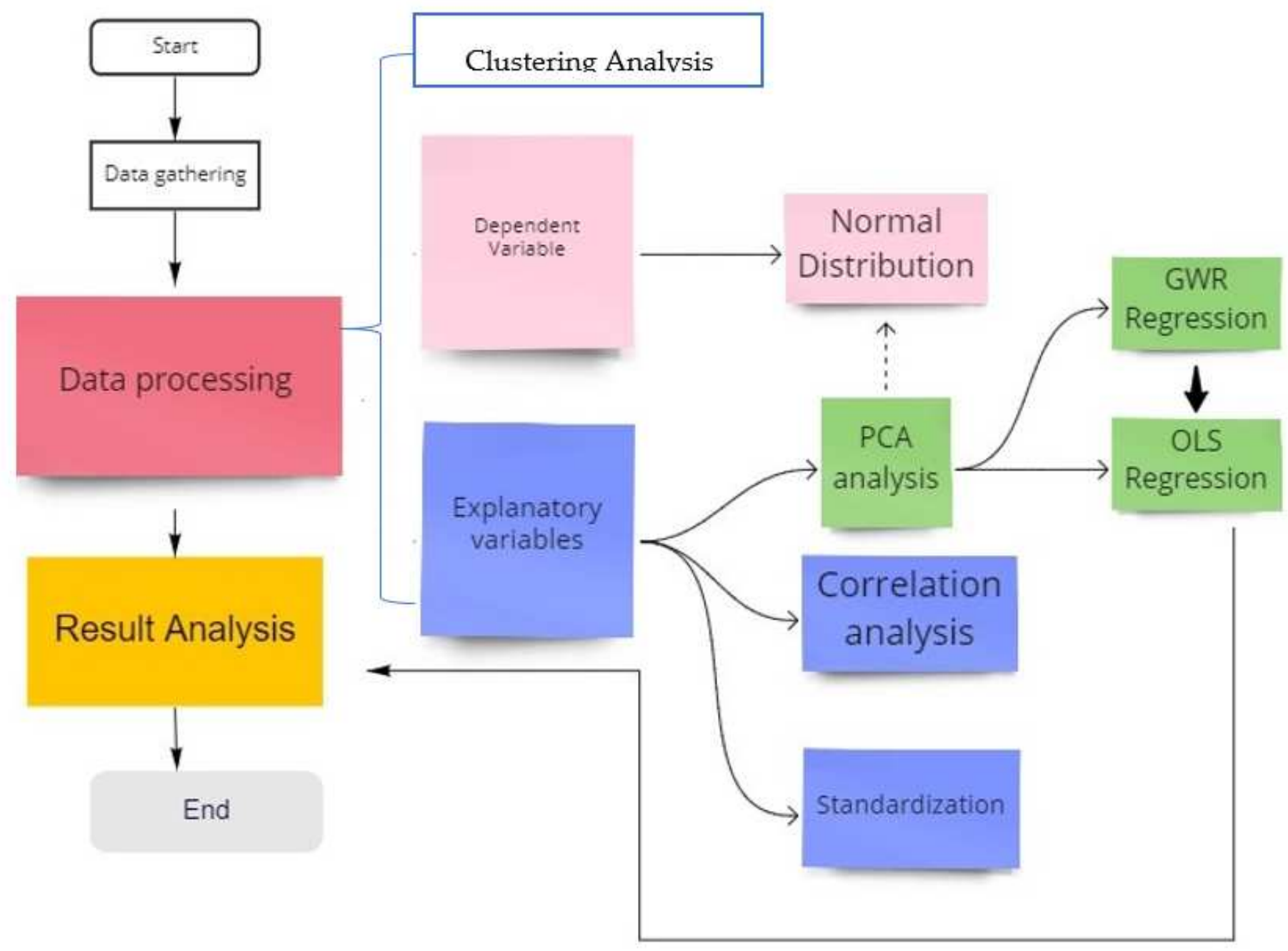

Figure 2

Spatial study framework 


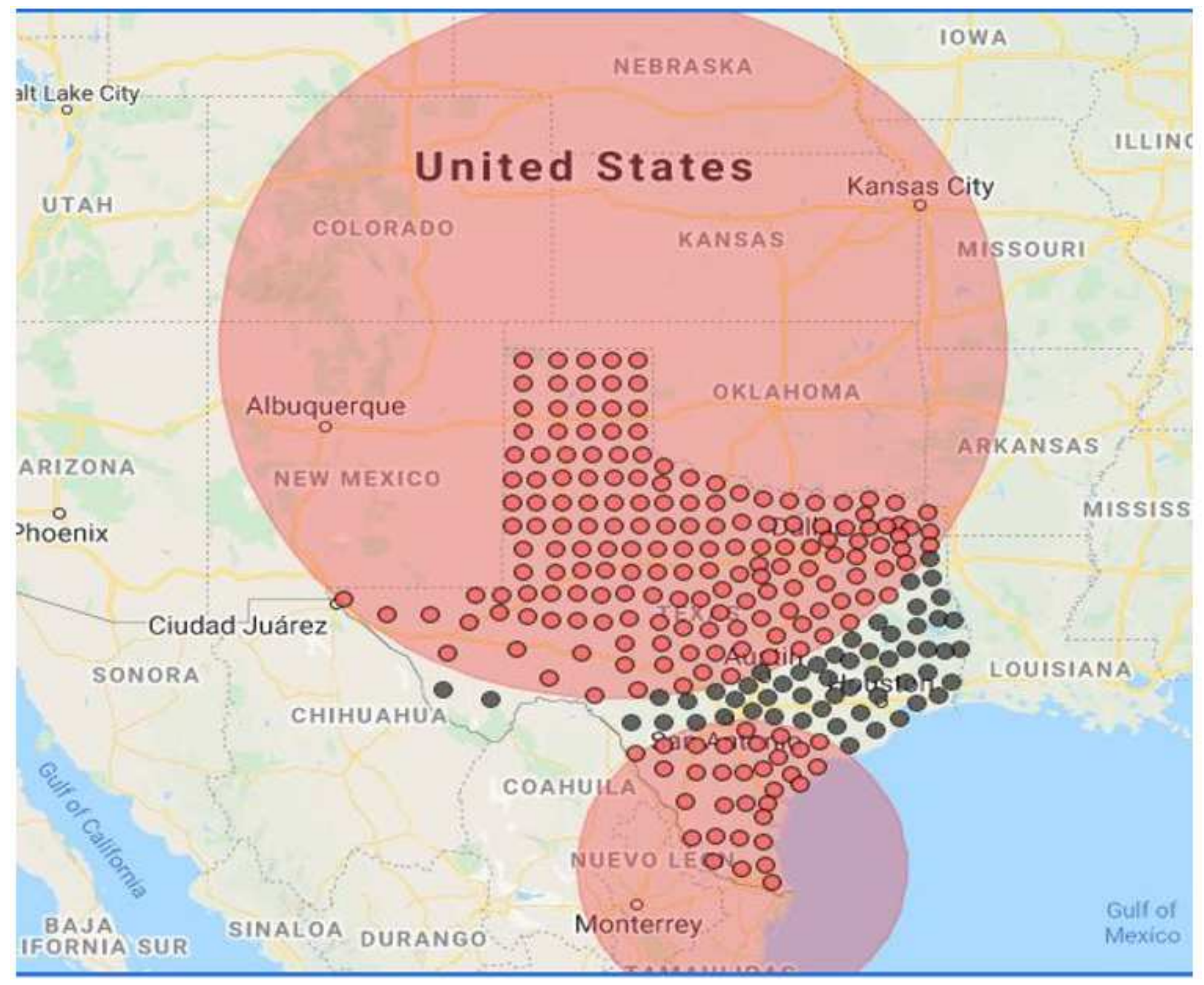

\section{Figure 3}

Space-time clusters distribution Map Note: The designations employed and the presentation of the material on this map do not imply the expression of any opinion whatsoever on the part of Research Square concerning the legal status of any country, territory, city or area or of its authorities, or concerning the delimitation of its frontiers or boundaries. This map has been provided by the authors. 


\section{Cluster \#1}

Cluster Observed (Outside Cluster) - Expected (Outside Cluster)

Observed (Inside Cluster) - Expected (Inside Cluster)

- Observed / Expected (Outside Cluster) - Observed / Expected (Inside Cluster)

$8 \mathrm{k}$

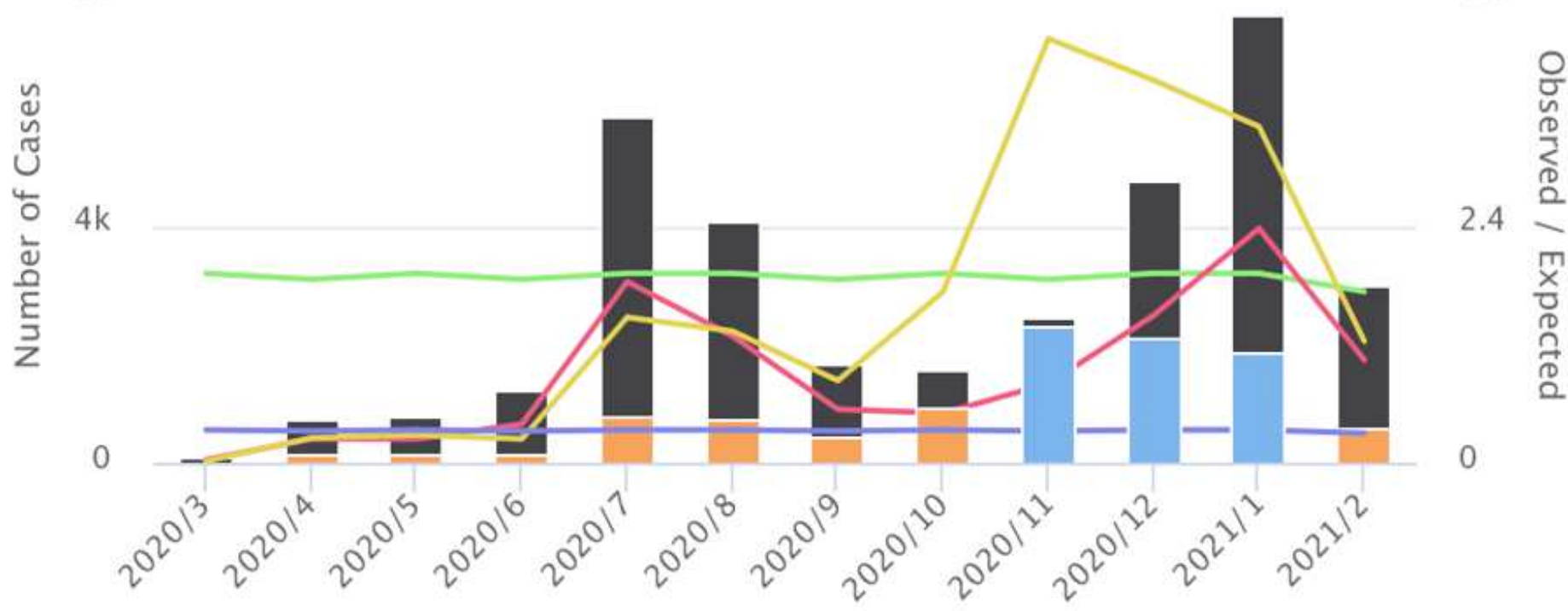

Figure 4

Temporal trend

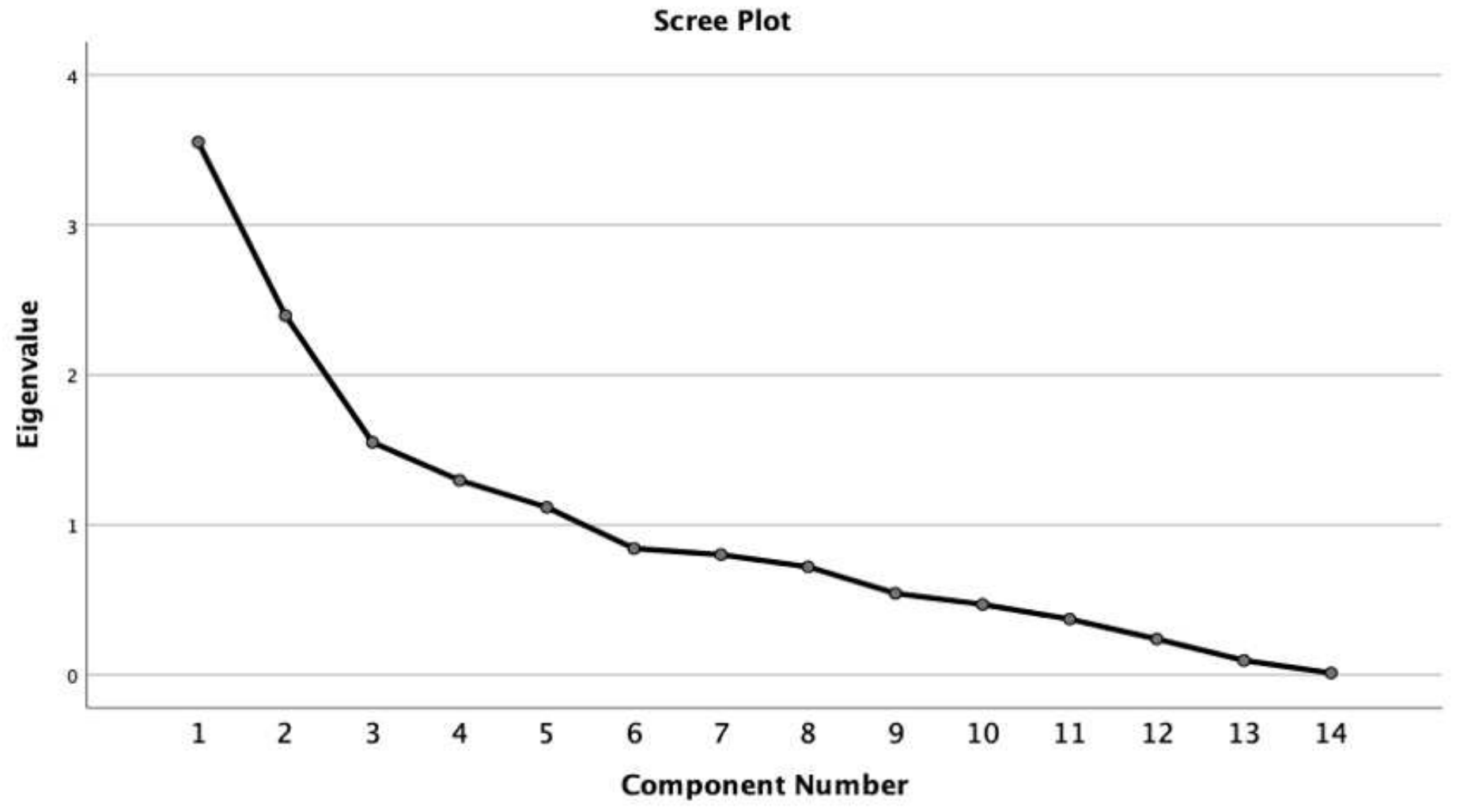


Figure 5

Component factors extracting

\begin{tabular}{|c|c|c|c|}
\hline Factor & $\begin{array}{l}\text { The Third Quarter GWR } \\
\text { Map in } 2020\end{array}$ & $\begin{array}{l}\text { The Fourth Quarter GWR } \\
\text { Map in } 2020\end{array}$ & $\begin{array}{l}\text { The Fourth Quarter GWR } \\
\text { Map in } 2021\end{array}$ \\
\hline $\begin{array}{l}\text { Population \& Hospi- } \\
\text { talization }\end{array}$ & 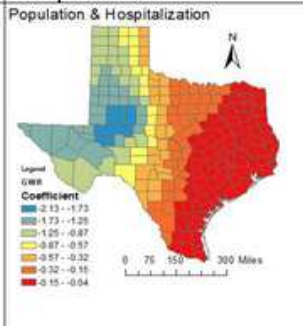 & Population \& Hospitalization & Population \& Hospitalization \\
\hline Adult Population & 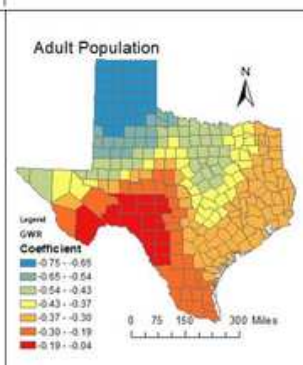 & 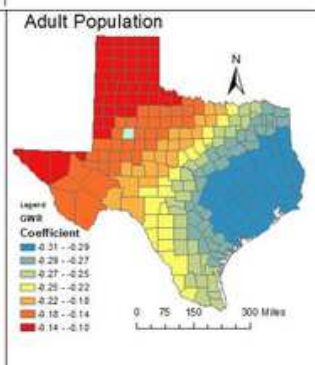 & 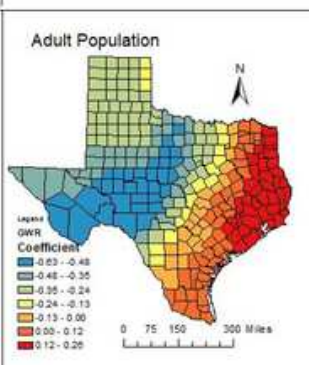 \\
\hline Land Area & 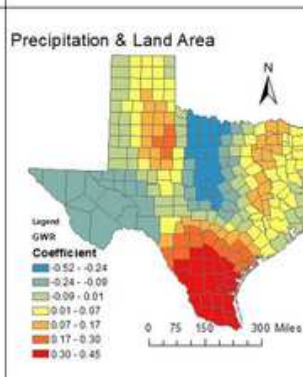 & 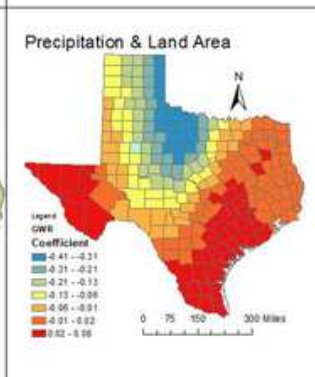 & 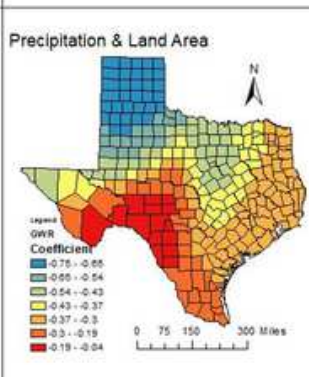 \\
\hline $\begin{array}{l}\text { Economical- } \\
\text { Condition }\end{array}$ & 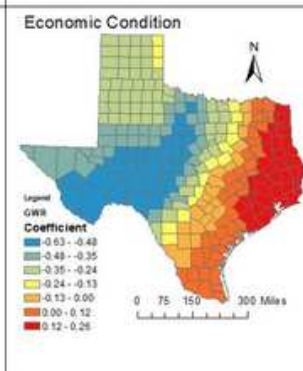 & 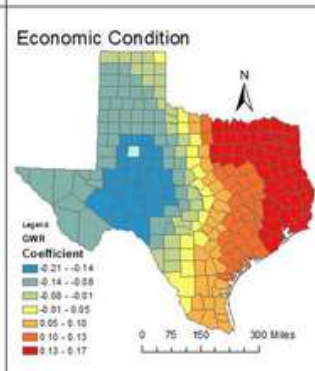 & 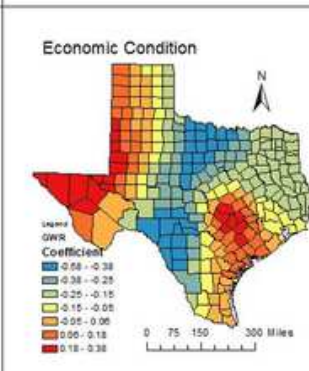 \\
\hline $\begin{array}{l}\text { Air Quality in } \\
\text { Q3 and Q1 but } \\
\text { Medical Sup- } \\
\text { ply in Q4 }\end{array}$ & 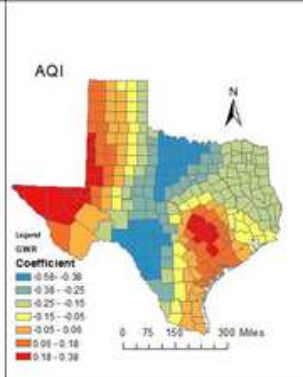 & 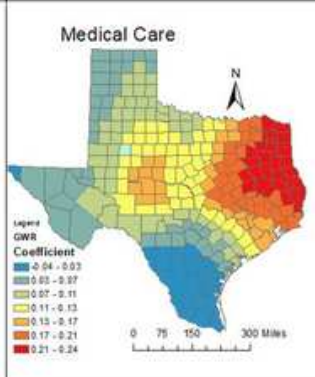 & 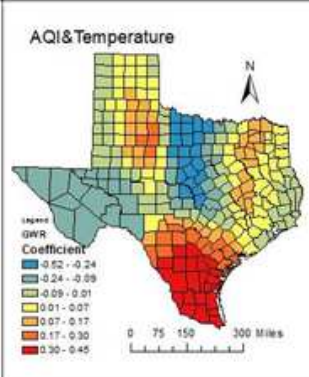 \\
\hline
\end{tabular}

Figure 6

Spatial-temporal GWR Map Note: The designations employed and the presentation of the material on this map do not imply the expression of any opinion whatsoever on the part of Research Square concerning 
the legal status of any country, territory, city or area or of its authorities, or concerning the delimitation of its frontiers or boundaries. This map has been provided by the authors.

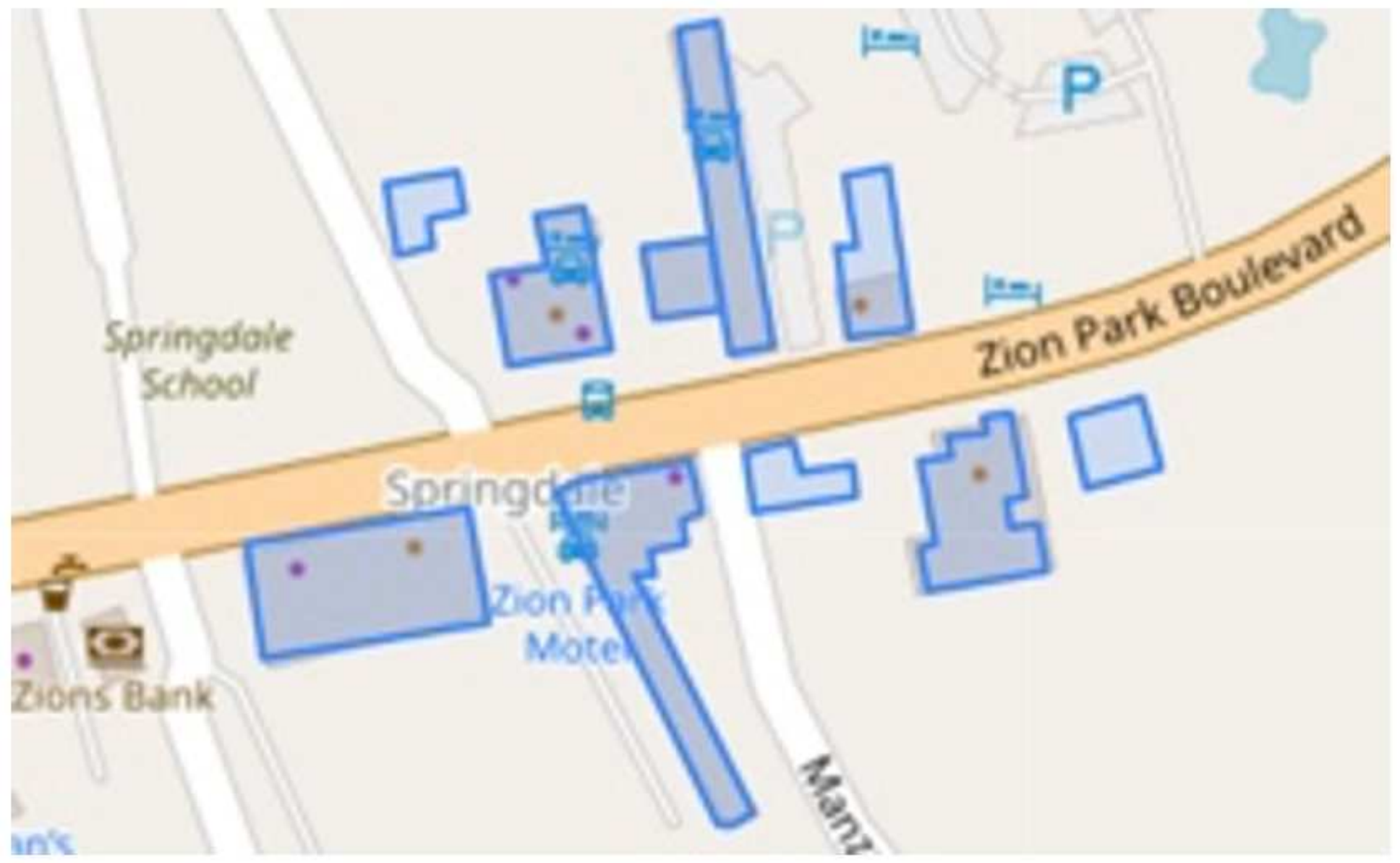

\section{Figure 7}

Tracing Map of Pioneer Lodge Motel Note: The designations employed and the presentation of the material on this map do not imply the expression of any opinion whatsoever on the part of Research Square concerning the legal status of any country, territory, city or area or of its authorities, or concerning the delimitation of its frontiers or boundaries. This map has been provided by the authors. 